\title{
Bond Strength of Grouted Reinforcing Bars
}

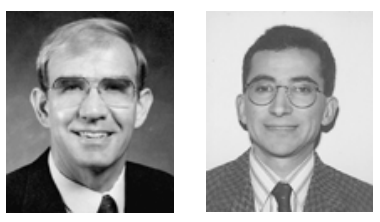

\section{by David Darwin and Shahin S. Zavaregh}

The effects of hole preparation method, grout type, hole diameter, bar size, embedment length, cover, bar surface condition (epoxy-coated or uncoated), orientation of the installed bar, and concrete strength on the bond strength of grouted reinforcing bars are described. Hole preparation methods, using a high-speed vacuum drill or a hand-held electric hammer drill, and cleaning methods, using a fiber bottle brush with water, a fiber bottle brush without water, or compressed air only are compared. Two capsule systems, two two-component grout systems, and two nonshrink grout systems are evaluated. Hole diameters range from 3/4 to 1-1/2 in. (19 to $38 \mathrm{~mm}$ ) for No. $5(16 \mathrm{~mm})$ bars; a hole diameter of 1-1/4 in. (32 $\mathrm{mm})$ is used for No. $8(25 \mathrm{~mm})$ bars. Embedment lengths range from 4 to $12 \mathrm{in}$. (102 to $305 \mathrm{~mm}$ ) for No. 5 (16 mm) bars and from 6 to $15 \mathrm{in}$. (150 to $380 \mathrm{~mm}$ ) for No. 8 (25 mm) bars. 1-1/2 and 3 in. (38 and $75 \mathrm{~mm}$ ) covers are used. Bar installations include vertical, sloped, and horizontal bars. Test results are used to develop rational design and construction requirements.

The bond strength of grouted reinforcing bars is not highly sensitive to differences in the hole preparation or cleaning methods studied. Grouts that provide strong bond at the grout-concrete interface provide higher bond strengths than grouts that undergo failure at the grout-concrete interface. With the exception of bars anchored by capsule systems, the bond strength provided by grouts is not sensitive to hole diameter. Bond strength increases with increasing embedment length, cover, and bar size. The bond strength of grouted reinforcement is insensitive to the presence of epoxy coating. Vertically and horizontally anchored bars may exhibit different bond strengths, depending on the grout used.

Keywords: adhesives; bond (concrete to reinforcement); coatings; embedment; grout; reinforcing steels; structural engineering.

Grouting reinforcement into holes drilled in existing concrete is commonly specified in the repair and retrofit of reinforced concrete structures. The procedure is widely used in highway construction to attach barriers and widen existing bridges, applications that involve relatively low cover on the grouted bars. In spite of its widespread use, little data exists on the bond strength of grouted reinforcement to concrete, and no data exists for bars with low cover. This lack of data has prevented the development of rational anchorage design procedures. Designers usually make use of proprietary design tables provided by grout manufacturers. These tables provide strengths that are based on highly confined pullout specimens. The strengths are then typically reduced by a factor of safety to establish "allowable" anchorage strengths. The strengths and modes of failure exhibited by highly confined specimens do not, however, match those obtained by grouted bars loaded under realistic conditions. ${ }^{1}$
Prior to the current study, there have been limited efforts to establish the strength of grouted reinforcement. ${ }^{2,3}$ This earlier work has involved reinforcing bars with very high cover, such as those used for concrete anchors. The use of high cover is not representative of highway bridge construction, in which covers as low as 1-1/2 in. (38 mm) are used for grouted reinforcement. Thus, the previous work is not only limited, but because of the high cover provides unconservative values of strength. In addition, the previous work has used uncoated reinforcement rather than epoxy-coated reinforcement as used in most transportation structures today. The effect of epoxy coating on the bond strength of grouted reinforcement is thus largely unknown.

The behavior and design of both cast-in-place and retrofit concrete anchors have been thoroughly studied by Cook et al. ${ }^{4,5}$ Although that research does not specifically address grouted reinforcing bars, it provides a wealth of information on the subject of anchorage to concrete.

The purpose of this study is to develop a pool of data on the bond strength of grouted reinforcing bars and to use that data to develop rational design and construction requirements. The experimental program addresses the effects of hole preparation method, grout type, hole diameter, bar size, embedment length, cover, bar surface condition (epoxy-coated or uncoated), orientation of the installed bar, and concrete strength. This paper describes the overall experimental program, evaluates test results, and presents design and construction recommendations that will improve both the safety and the economy of grouted reinforcing bars. Details not covered in this paper are presented in Reference 1.

\section{Test specimens}

\section{EXPERIMENTAL PROGRAM}

The experimental program consisted of 492 reinforcing bars grouted or cast-in-place in beam-end specimens designed to provide realistic degrees of concrete confinement to match the behavior of grouted bars as used in practice (Fig. 1). The test specimens were cast in 23 groups of six to 12 concrete specimens each.

ACI Structural Journal, V. 93, No. 4, July-August 1996.

Received Feb. 23, 1995, and reviewed under Institute publication policies. Copyright (ㅇ 1996, American Concrete Institute. All rights reserved, including the making of copies unless permission is obtained from the copyright proprietors. Pertinent discussion will be published in the May-June 1997 ACI Structural Journal if received by Jan. 1, 1997. 
David Darwin, FACI, is the Deane E. Ackers Professor of Civil Engineering and Director of the Structural Engineering and Materials Laboratory at the University of Kansas. He is a past member of the Board of Direction and the Technical Activities Committee and is a past-president of the ACI Kansas Chapter. Darwin is Chairman of the Publications Committee, past-chairman of the Concrete Research Council, and a member and past-chairman of ACI Committee 224, Cracking. He is also a member of ACI Committees 408, Bond and Development of Reinforcement; 446, Fracture Mechanics; and ACI-ASCE Committees 445, Shear and Torsion, and 447, Finite Element Analysis of Reinforced Concrete Structures. He is a recipient of the Arthur R. Anderson Award and the ACI Structural Research Award.

ACI member Shahin S. Zavaregh is an engineer with the Iowa Department of Transportation. He received his $B S$ and $M S$ degrees in civil engineering from the University of Kansas.
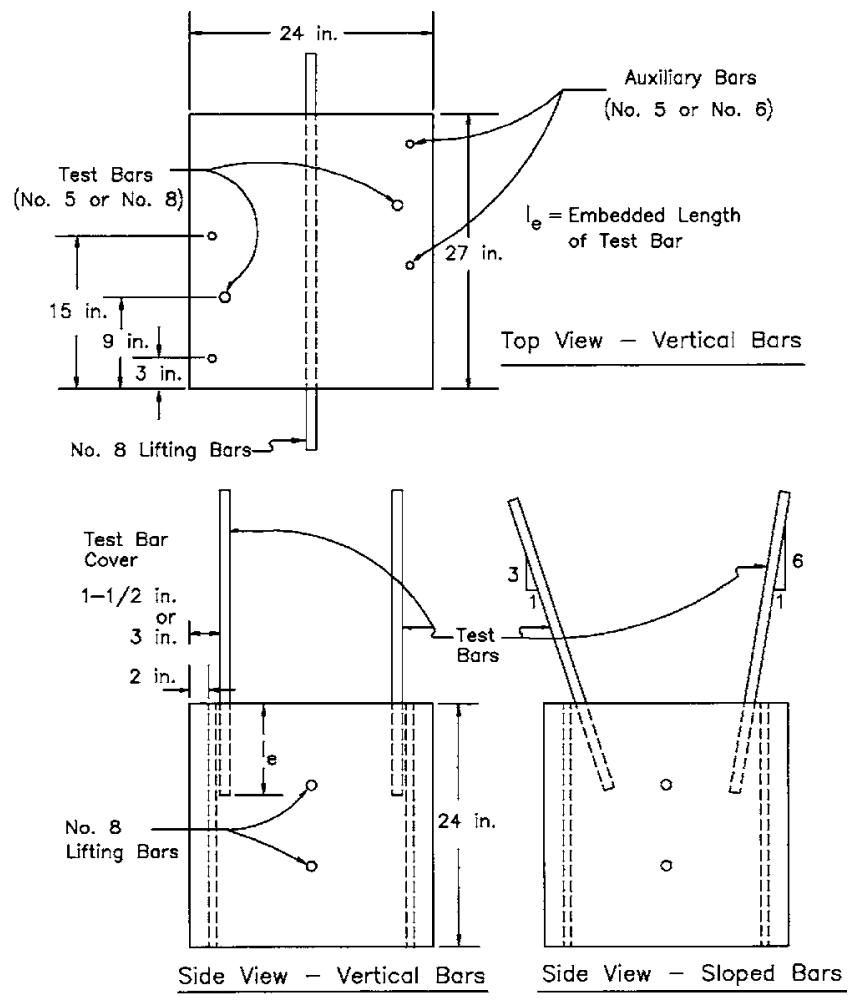

Fig. 1(a)-Test specimen with vertical or sloped bars as cast.

The basic test specimen consisted of a block of concrete 24-in. (610-mm) long by 27 -in. (686-mm) wide by 24 -in. (610-mm) high and contained two vertical or two sloped bars anchored on the upper surface [Fig. 1(a)] or two horizontal bars anchored on a vertical surface [Fig. 1(b)]. Some specimens contained as many as six test bars. As constructed and tested, the failure of individual bars was unaffected by other bars in the test specimen. No. 5 and No. 8 bars were used in this study.

Most bars had a 3 in. $(75 \mathrm{~mm}$ ) cover; selected bars had a 1-1/2 in. (38 mm) cover. Embedment lengths of 4, 6, 9, and 12 in. $(100,150,230$, and $305 \mathrm{~mm})$ were used for No. $5(16 \mathrm{~mm})$ bars, while embedment lengths of 6, 9, 12, and 15 in. (150, 230,305 , and $380 \mathrm{~mm}$ ) were used for No. $8(25 \mathrm{~mm})$ bars.

Based on experience with narrower test specimens, ${ }^{6,7}$ auxiliary reinforcement was added parallel to the test bars to provide additional tensile capacity to the concrete (Fig. 1). Two No. $5(16 \mathrm{~mm})$ auxiliary bars were used for No. $5(16 \mathrm{~mm})$ test bars, and two No. $6(19 \mathrm{~mm})$ auxiliary bars were used for No. $8(25 \mathrm{~mm})$ test bars. Auxiliary bars had $2 \mathrm{in} .(51 \mathrm{~mm})$ of
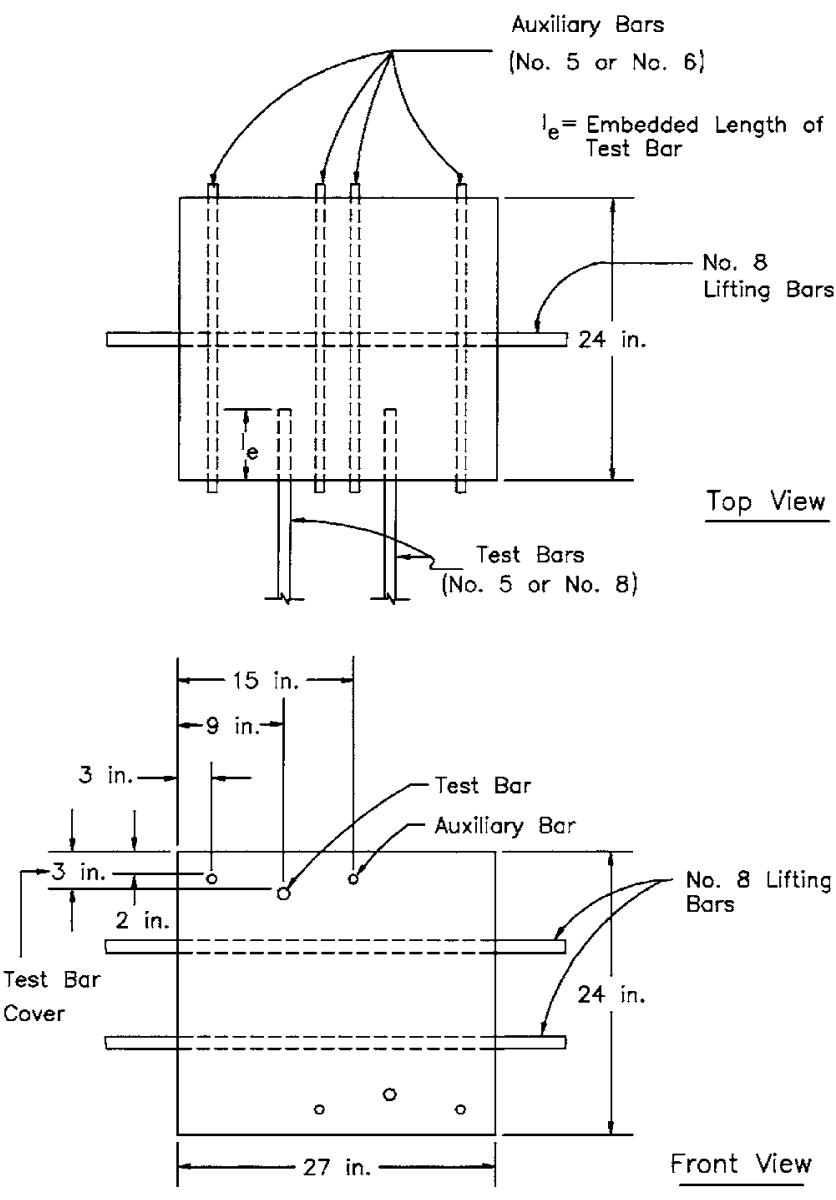

Fig. 1(b)-Test specimen with horizontal bars as cast.

cover and were centered 6 in. $(152 \mathrm{~mm})$ on either side of the test bars. Some test specimens, however, did not contain auxiliary reinforcement, and an analysis of the data later demonstrated that auxiliary reinforcement was not required and played no measurable role in specimen behavior or strength. ${ }^{1}$ Both epoxy-coated and uncoated bars were evaluated. Epoxy-coated reinforcement was used in most of the tests due to its wide application in transportation structures.

Grouted No. $5(16 \mathrm{~mm})$ bars were anchored in holes with diameters of $3 / 4,13 / 16,7 / 8$, and 1-1/2 in. $(19,21,22$, and $38 \mathrm{~mm})$, while grouted No. $8(25 \mathrm{~mm})$ bars were anchored exclusively in holes with diameters of 1-1/4 in. $(32 \mathrm{~mm}$ ). Most tests involved holes with diameters $1 / 4$ in. larger than the bar diameter [7/8 and 1-1/4 in. (22 and $32 \mathrm{~mm}$ ) for No. 5 and No. 8 (16 and $25 \mathrm{~mm}$ ) bars, respectively].

\section{Materials}

Reinforcing steel-ASTM A $615^{8}$ Grade 60 No. 5, No. 6 , and No. $8(16,19$, and $25 \mathrm{~mm})$ bars were used for the tests. Epoxy coating was commercially applied in accordance with ASTM A 775. ${ }^{9}$

Concrete-Air-entrained concrete was supplied by a local ready-mixed plant. Type I portland cement, $3 / 4$ in. nominal maximum size crushed limestone, and river sand were used to produce concretes with nominal strengths of 2700 or $5000 \mathrm{psi}$ (18.6 or $34.5 \mathrm{MPa}$ ). The majority of the tests were carried out at $5000 \mathrm{psi}(34.5 \mathrm{MPa})$. 


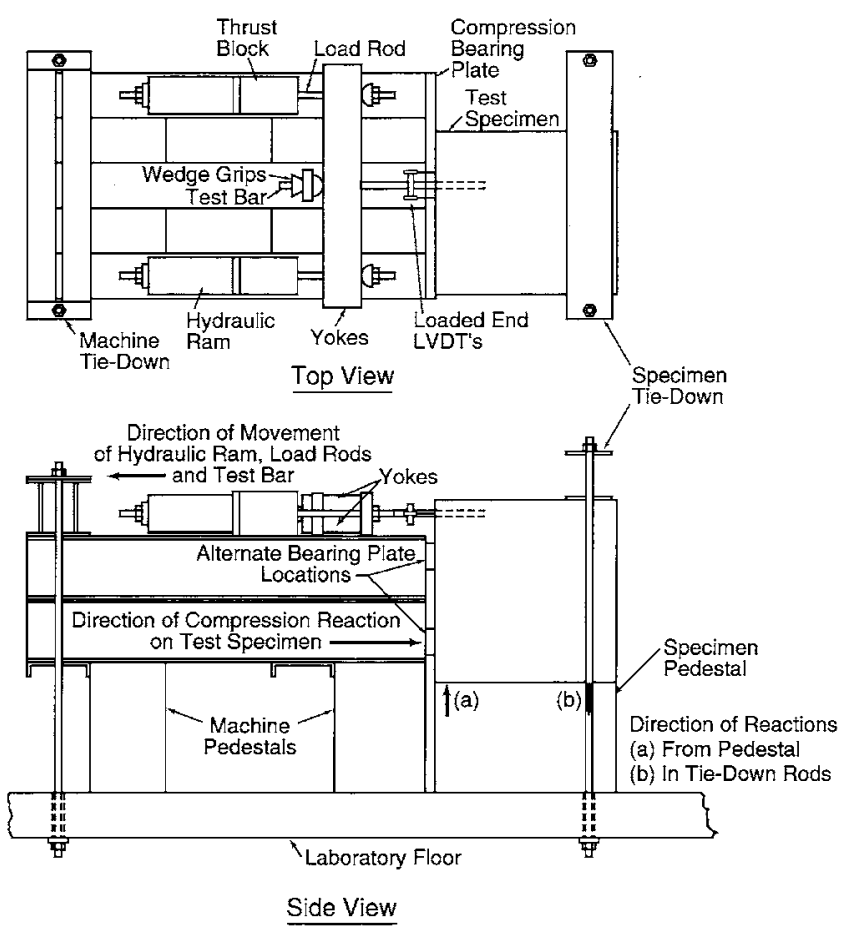

Fig. 2-Schematic of test setup.

Grout-Six grouts were evaluated in the study: two capsule systems (designated CPA, CPB); two two-component systems (TCA, TCB); and two nonshrink grouts (NSA, NSB). CPA consisted of a vinyl ester resin system, and CPB consisted of a polyester resin system. The capsule systems contained microaggregate, and the size of the capsules depended on the size of the bar being anchored. TCA consisted of a vinyl ester resin system, while TCB consisted of an epoxy resin system. NSA and NSB consisted of nonmetallic cementitious nonshrink grout systems. The study placed major emphasis on four of the grouting systems: CPA, TCA, TCB, and NSA.

\section{Bar installation}

A high-speed, hydraulic, truck-mounted vacuum drill and a hand-held electric rotary hammer drill were used to place holes in the specimens. The self-cleaning vacuum drill has been used for over 15 years by the Kansas Department of Transportation to add shear reinforcement to bridges. ${ }^{10,11}$ It was evaluated to see if it provided any advantages over the more traditional hand-held drill, which was used to prepare most of the test specimens. A shop vacuum cleaner was used in conjunction with the hand-held drill to remove cutting debris at the top of the hole.

Four cleaning methods were evaluated in the study: 1) using the truck-mounted vacuum drill, with no additional hole preparation $(\mathrm{V})$; 2) vacuuming the bottom of the hole with a shop vacuum cleaner with a $1 / 2$ in. outside diameter nozzle, followed by thorough scrubbing with a fiber bottle brush and water and blowing out the hole with compressed air (BW); 3) vacuuming with the shop vacuum cleaner, brushing with the fiber bottle brush (no water), and blowing out the hole with compressed air (BA); and 4) vacuuming the hole with the shop vacuum cleaner and blowing out the hole with compressed air (A). An in-line filter removed oil and water from the compressed air. Methods BW, BA, and A were used for holes made with the hand-held drill.

Grouts and reinforcing bars were placed according to the manufacturer's instructions. ${ }^{1}$ A manual dispenser provided by the manufacturer was used to place TCA grout, which was prepackaged for automatic proportioning during installation. TCB grout was batched by volume (two parts A to one part B) and mixed for 3 min according to the manufacturer's instructions. In the plastic state, TCA had the consistency of toothpaste and set rapidly, while TCB had the consistency of honey and set slowly. As a result, TCA could be used in both vertical and horizontal holes, while TCB, without the addition of a filler or special provision to prevent leakage in horizontal holes, could be used only in vertical holes.

The capsule systems, CPA and CPB, contained two components sealed in glass tubes. The individual capsules were placed in holes, and the reinforcing bar, with a chisel point (45 deg angle), was attached to the hammer drill with a special drive socket and drilled to the bottom of the hole.

The nonshrink grouts were mixed until uniform. The NSA and NSB grouts were combined with 1.5 and 2.55 gal. $(5.7 \times$ $10^{-3}$ and $\left.9.7 \times 10^{-3} \mathrm{~m}^{3}\right)$ of water, respectively, per $55 \mathrm{lb}(25 \mathrm{~kg})$ bag of material to produce grout with a fluid consistency.

To avoid air pockets and insure complete filling of a hole, grouts were poured down one side of the hole and placement was completed without interruption. Bars were inserted by hand after placement of the two-component and nonshrink grouts. Following insertion of the reinforcing bar, exposed surfaces were sealed with duct tape. Grouts were cured for a minimum of 3 days.

\section{Test procedure}

The test system, illustrated in Fig. 2, was used to apply load at approximately 3 kips $(13 \mathrm{kN})$ per min for No. $5(16 \mathrm{~mm})$ bars and 6 kips $(27 \mathrm{kN})$ per min for No. $8(25 \mathrm{~mm})$ bars. The tensile force on the test bar was counteracted by a compressive force imposed on the concrete specimen through a 4 in. $(102 \mathrm{~mm})$ deep steel bearing plate. The edge of the plate was located 4-1/2 in. (114 $\mathrm{mm}$ ) below the center of the test bars, except for selected specimens for which the spacing was increased to 12 in. $(305 \mathrm{~mm})$ to evaluate the effects of changes in degree of confinement provided to the test bar based on the proximity of the bearing plate. Loaded-end slip was measured using two spring-loaded linear variable differential transformers (LVDTs) attached to an aluminum block mounted on the test bar 4 in. $(102 \mathrm{~mm})$ from the face of the concrete. The orientation of specimens with sloped bars [Fig. 1(a)] was adjusted and shims were used to adjust the bearing plate so that the test bars could be placed in direct tension.

\section{SPECIMEN BEHAVIOR AND ANALYSIS OF TEST RESULTS}

To account for differences in concrete strength, experimental bond strengths are multiplied by $\left(5000 / f_{c}^{\prime}\right)^{1 / 2}\left[f_{c}^{\prime}\right.$ in psi] to obtain "modified bond strengths" that are used for comparison and analysis. The term "bond strength" represents the maximum tensile force $T_{e}$ attained during a test. 


\section{Failure modes}

The test specimens exhibited five failure modes. In many cases, failure involved a combination of these modes. Most of the test specimens exhibited a splitting failure (tensile cracks in the concrete parallel to the reinforcing bar), shown in Fig. $3(\mathrm{a})$, or a failure at the interface between the grout and the concrete (IGC failure), shown in Fig. 3(b). These failure modes often occurred in conjunction with the formation of a shallow angle concrete cone surrounding the reinforcing bar on the face of the specimen, also shown in Fig. 3(b). Some specimens exhibited a tensile failure mode in which the concrete test specimen failed due to tensile/flexural cracks perpendicular to the direction of loading, while some specimens exhibited no sign of failure other than bar pullout.

Splitting failure is the type of bond failure exhibited by most cast-in-place reinforcing bars in structural applications $^{12-15}$ and was the primary mode of failure for bars anchored with Capsule B (CPB), Two-Component Grout B (TCB), Nonshrink Grout A (NSA), Nonshrink Grout B (NSB), and No. 8 bars anchored with Capsule A (CPA). For cast-in-place bars, splitting failures are governed primarily by the strength of the concrete and any confining reinforcement, such as stirrups or ties ${ }^{16,17}$ (confining reinforcement was not used in this study). For grouted bars, a splitting failure indicates close interaction between the grout and the surrounding concrete and is usually accompanied by failure at the reinforcing bar-grout interface, not the groutconcrete interface.

Failure at the interface between grout and concrete (IGC) indicates a low bond strength between the two materials. This type of failure generally results in a lower anchorage strength than a splitting failure. IGC was the primary mode of failure for bars anchored with Two-Component Grout A (TCA).

Pullout was the primary mode of failure for No. 5 bars anchored with CPA.

The failure modes obtained for bars for which the steel bearing plate was moved from 4-1/2 to $12 \mathrm{in}$. (114 to $305 \mathrm{~mm}$ ) below the center of the test bars showed no significant differences from those obtained in the balance of the tests, indicating little difference in the degree of confinement provided to the bars based on the two bearing plate positions.

The following sections cover the effects of bar surface condition, hole diameter, hole preparation method, bonding system, embedment length, bar diameter, cover, bar orientation, and concrete strength. The full test results ${ }^{1}$ are summarized in Appendix A.

\section{Bar surface condition, hole diameter, hole preparation method, and bonding method system}

Six test groups (three each for vertically anchored No. 5 and No. 8 [16 and $25 \mathrm{~mm}$ ] bars) were selected to evaluate the effects of bar surface condition, hole diameter, hole preparation method, and bonding system on bond strength. The bars had a nominal cover of 3 in. $(75 \mathrm{~mm})$ and embedded lengths of 6 and 9 in. (150 and $330 \mathrm{~mm}$ ) for No. 5 and No. 8 bars, respectively. No. 5 bars were used to evaluate the effects of hole

*The Appendix is available in xerographic or similar form from ACI headquarters, where it will be kept permanently on file, at a charge equal to the cost of reproduction plus handling at time of request.

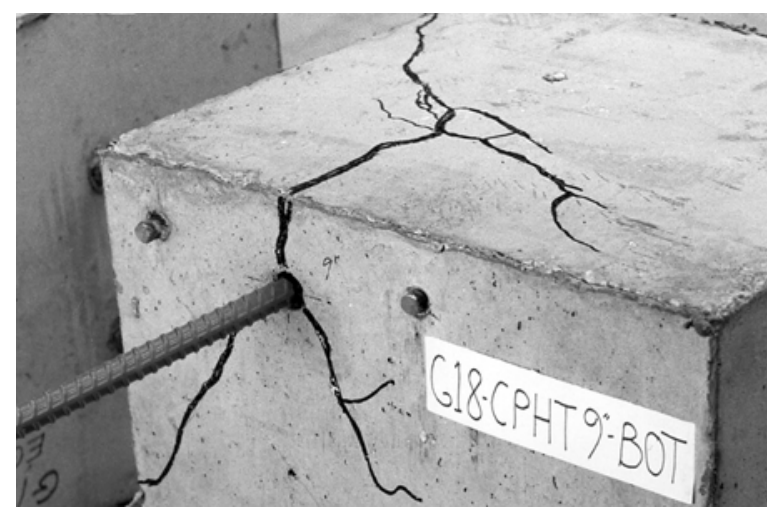

(a)

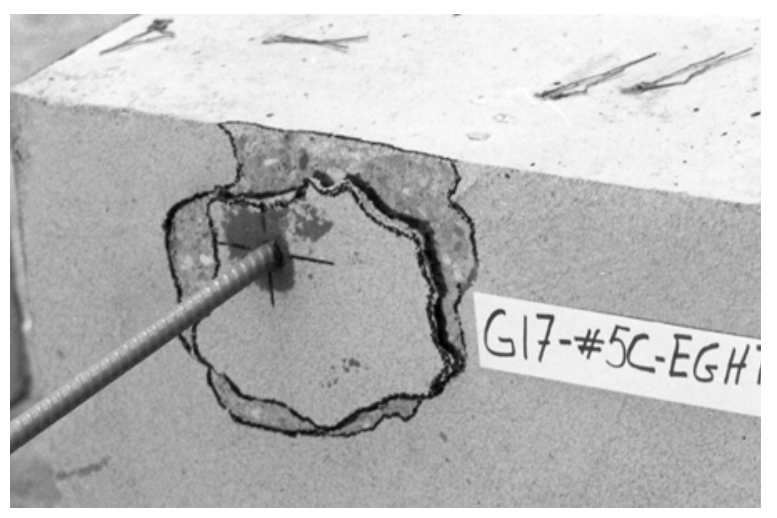

(b)

Fig. 3-Test specimens at failure: (a) splitting failure; (b) combined cone failure and failure at interface between grout and concrete (IGC).

diameter. The results are summarized in Tables 1 and 2. The mean bond strengths listed in the tables are averages for three specimens, each of the three taken from a different test group.

Surface condition-Results indicate no significant effect of epoxy coating on the bond strength of grouted reinforcement. Comparisons of coated and uncoated bars are made in Table 1 for No. 5 bars with Nonshrink Grout A (NSA) and Two-Component Grout A (TCA). Of the four comparisons shown in the table, the uncoated bars (marked $\mathrm{M}$ for mill scale surface) provide a higher bond strength in one case, the epoxy-coated bars (marked E) provide a higher bond strength in two cases, and the two surface conditions provide nearly identical strengths in the fourth case.

Hole diameter - Increased hole diameter is often considered to result in a decreased bond strength. ${ }^{18}$ To determine the effect of hole diameter on bond strength, No. $5(16 \mathrm{~mm})$ bars were grouted in $7 / 8 \mathrm{in}$. $(22 \mathrm{~mm}$ ) diameter and 1-1/2 in. (38 mm) diameter holes using the two nonshrink grouts (NSA and NSB) and the two two-component grouts (TCA and TCB). The capsule systems were not used in the comparison due to their dependence on a small hole diameter for proper performance.

For the six comparisons shown in Table 1, the small diameter hole produced a higher strength in two cases, and the large diameter hole produced a higher strength in three cases. The results were nearly identical in the sixth case. The overall 
Table 1-Mean bond strength* (kips) as affected by bar surface condition, hole diameter, and hole preparation method for grouted No. $5(16 \mathrm{~mm})$ bars

\begin{tabular}{c|c|c|c}
\hline \multirow{2}{*}{ Bar surface grout $^{\dagger}$} & \multirow{2}{*}{$\begin{array}{c}\text { Hole preparation method: } \\
\text { rotary hammer drill }\end{array}$} & \multicolumn{2}{|c}{ Hole diameter } \\
\cline { 3 - 4 } & Small & Large \\
\hline E-CPA & BW $^{\S}$ & 11.0 & - \\
\hline E-CPB & BW & 9.7 & - \\
\hline M-NSA & BW & 15.1 & 14.2 \\
\hline & BA & - & 15.3 \\
\hline E-NSA & A & - & 15.5 \\
\hline E-NSB & BW & 13.1 & 14.9 \\
\hline M-TCA & BW & 14.2 & 14.1 \\
\hline E-TCA & BW & 10.3 & 12.4 \\
\hline E-TCB & BW & 11.7 & 12.5 \\
\hline A & BW & 15.8 & 15.0 \\
\hline
\end{tabular}

*Average of three tests; nominal concrete strength $=5000 \mathrm{psi}(34.4 \mathrm{MPa})$; embedded length $=6$ in. $(150 \mathrm{~mm})$; vertical placement.

${ }^{\dagger} \mathrm{E}=$ epoxy-coated; $\mathrm{CPA}=$ capsule grout system; $\mathrm{NSA}=$ nonshrink grout; $\mathrm{NSB}=$ nonshrink grout; TCA = stiff two-component grout; $\mathrm{TCB}=$ fluid two-component grout.

${ }^{+}$Small $=7 / 8$ in. $(22 \mathrm{~mm})$, except $=13 / 16$ in. $(21 \mathrm{~mm})$ for CPA and $3 / 4$ in. $(19 \mathrm{~mm})$ for CPB; large $=1-1 / 2$ in. $(38 \mathrm{~mm})$.

${ }_{\mathrm{BW}} \mathrm{BW}$ brush with water followed by compressed air; $\mathrm{BA}=$ brush and compressed air; $\mathrm{A}=$ compressed air only

Note: $1 \mathrm{kip}=4.45 \mathrm{kN}$

conclusion is that for the four grouting systems evaluated, hole diameter does not play a role in bond strength. It is, of course, important to remember that an increased hole diameter requires a greater amount of grout, reducing the economy of the system, and that the bond strength of capsule systems can be very sensitive to hole diameter, as will be demonstrated later in the paper.

Hole preparation-Hole preparation involved the use of either a vacuum drill or a hand-held rotary hammer drill. When the vacuum drill (V) was used, no additional hole preparation was used. With the hand-held drill, the holes were first cleaned with a shop vacuum. The openings were then cleaned with 1) a fiber brush and water, allowed to dry, and then cleaned with compressed air (BW); 2) a fiber brush without water, followed by compressed air (BA); or 3) with compressed air only (A). Bond strengths, as affected by preparation method, are compared in Table 1 for uncoated No. 5 $(16 \mathrm{~mm})$ bars with Nonshrink Grout A (M-NSA), cast in $1-1 / 2$ in. $(38 \mathrm{~mm})$ diameter holes, and in Table 2 for epoxycoated No. $8(25 \mathrm{~mm})$ bars cast with Capsule System A (E-CPA), Nonshrink Grout System A (E-NSA), and TwoComponent Grout Systems A and B (E-TCA and E-TCB). The vacuum drilling system $(\mathrm{V})$ was used only for the No. 8 bars.

As shown in Table 1, the brush with water (BW) cleaning system provides a slightly lower bond strength for the NSA grout than does either the brush with air (BA) or compressed air (A) alone, which provide nearly identical strengths. However, the differences are not significant.

The comparisons in Table 2 for No. $8(25 \mathrm{~mm})$ bars show no statistically significant differences based on hole preparation method, with the exception of the bars anchored with Two-Component System A (TCA). The TCA grout is a stiff, rapid-setting polymer system that does not readily wet (penetrate) concrete surfaces. It provides a bond strength comparable to that provided by the other grouts when used in holes prepared with the vacuum drill. However, its bond
Table 2-Mean bond strength* (kips) as affected by hole preparation for grouted No. $8(25 \mathrm{~mm})$ bars

\begin{tabular}{c|c|c|c|c}
\hline Bar surface grout $^{\dagger}$ & E-CPA & E-NSA & E-TCA & E-TCB \\
\hline Hole preparation method $^{\ddagger}$ & & & & \\
\hline Vacuum drill V $^{\text {Rotary hammer drill }}$ & 25.7 & 24.8 & 23.4 & 24.9 \\
\hline BW & 26.7 & 25.2 & 16.6 & 24.7 \\
\hline BA & 28.2 & 23.2 & 14.6 & 24.9 \\
\hline A & 27.5 & 23.9 & 16.8 & 24.8 \\
\hline
\end{tabular}

*Average of three tests; nominal concrete strength $=5000$ psi $(34.4 \mathrm{MPa})$; embedded length $=9$ in. $(230 \mathrm{~mm})$; vertical placement

${ }^{\dagger} \mathrm{E}=$ epoxy-coated; $\mathrm{CPA}=$ capsule grout system; $\mathrm{NSA}=$ nonshrink grout NSB $=$ nonshrink grout; TCA = stiff two-component grout; TCB = fluid two-component grout.

${ }^{\ddagger} \mathrm{V}=$ truck-mounted vacuum drill; BW = brush with water followed by compressed air; BA = brush and compressed air; A = compressed air only.

Note: 1 kip $=4.45 \mathrm{kN}$.

strength drops about one-third when anchored in holes prepared with the hand-held drill and cleaned with one of the other three methods. The lower strength may be due to the presence of residual drilling debris on the concrete surface, not removed by the BW, BA, or A cleaning methods. This observation is reinforced by the failure modes of the test specimens. The TCA bars anchored in holes prepared using the hand-held drill and the BW, BA, or A cleaning method exhibited a failure at the interface between the grout and the concrete (IGC). The bars anchored with the TCA system in the holes prepared with the vacuum drill and all three of the other anchoring systems for all hole preparation methods exhibited a splitting failure, indicating a better bond between grout and concrete.

These results show that for most systems a reasonable effort to clean the hole will provide adequate bond between the grout and the concrete. However, some grout systems are sensitive to the hole preparation method and should be evaluated based on the preparation specified for use in the field.

Bonding system - A review of Tables 1 and 2 indicates that, for the systems evaluated, there can be measurable differences in bond strength. In the case of the No. $5(16 \mathrm{~mm})$ bars, the two capsule systems provided generally lower strengths than the other systems. In contrast, for the No. 8 $(25 \mathrm{~mm})$ bars, the capsule system (CPA) provided the highest strengths, although in the latter case the differences in strength between CPA and the NSA or TCB grouts are not statistically significant. As will be demonstrated next, however, the accurate evaluation of a grout system requires an understanding of the bond strength produced by the system as a function of embedment length, bar diameter, and concrete cover.

\section{Embedment length, bar diameter, and cover}

A prime goal of this study is to determine the effects of the key structural parameters, embedment length, bar diameter, and cover, on the bond strength of grouted reinforcing bars. It is generally acknowledged that the bond strength of cast-inplace reinforcing bars decreases as cover decreases. ${ }^{16,17}$ The majority of the tests in the current study were carried out with 3 in. $(75 \mathrm{~mm})$ cover, the minimum recommended for grouted reinforcing bars in most bridge installations. ${ }^{19} \mathrm{~A}$ small number of tests were carried out with $1-1 / 2$ in. $(38 \mathrm{~mm})$ 
cover. The comparisons that follow are based on bars grouted in vertical holes prepared using the BA cleaning method.

Embedment length-The effect of embedment length $\ell_{e}$ on the modified bond strength $T_{e}$ of vertically anchored No. 5 and No. 8 (16 and $25 \mathrm{~mm}$ ) bars is illustrated in Fig. 4. Embedment lengths of 4, 6, 9, and 12 in. (100, 150, 230, and $305 \mathrm{~mm})$ are used for No. $5(16 \mathrm{~mm})$ bars. Embedment lengths of $6,9,12$, and 15 in. (150, 230, 305, and $380 \mathrm{~mm})$ are used for No. $8(25 \mathrm{~mm})$ bars. The figure shows the modified bond strengths and the best-fit lines for uncoated (M) and epoxy-coated (E) cast-in-place bars and epoxy-coated TCA and TCB-grouted bars. The relationships between bond strength and embedment length are nearly linear.

Overall, uncoated cast-in-place bars provide the highest strengths, followed by coated cast-in-place bars, bars anchored with TCB grout, and, finally, bars anchored with TCA grout, although the epoxy-coated (E) cast-in-place (CIP) No. 5 bars exhibit higher strengths than the uncoated (M) CIP No. 5 bars for $\ell_{e}=9$ to 12 in. (230 to $305 \mathrm{~mm}$ ).

For both No. 5 and No. 8 (16 and $25 \mathrm{~mm}$ ) bars, the bond strength of the TCB-anchored bars is similar to the strength of the epoxy-coated cast-in-place (E-CIP) bars. Based on best-fit lines, the TCB/E-CIP strength ratio ranges from 1.10 to 0.91 with increasing embedment length for No. 5 bars, and from 0.985 to 0.975 for No. 8 bars.

The bond strength of TCA-anchored bars is significantly lower than the bond strengths of TCB-anchored bars. Based on the best-fit lines, the TCA/E-CIP strength ratio is nearly constant, 0.73 to 0.74 , for No. 5 bars and ranges from 0.67 to 0.79 for No. 8 bars.

Bar diameter-The effect of bar diameter on bond strength is also illustrated in Fig. 4, which shows that the No. 5 (16 mm) bars have lower bond strengths than the No. 8 (25 $\mathrm{mm})$ bars. The effect of bar diameter is greater for the cast-in-place and TCB-grouted bars than for the TCA-grouted bars. For embedment lengths of 6 and 12 in. (150 and $305 \mathrm{~mm}$ ), respectively, the No. 5/No. 8 strength ratios are 0.82 and 0.76 for uncoated (M) cast-in-place bars, 0.88 and 0.94 for epoxycoated (E) cast-in-place bars, 0.90 and 0.87 for TCB-grouted bars, and 0.97 and 0.90 for TCA-grouted bars, based on the best-fit lines. This effect of bar size on bond strength is similar to that observed for spliced cast-in-place bars. ${ }^{16,17}$

Cover-The effect of cover on bond strength is evaluated for uncoated and epoxy-coated cast-in-place and epoxycoated TCA and TCB-anchored No. 5 (16 mm) bars in Fig. 5. The reduction in concrete cover from 3 to $1-1 / 2$ in. (75 to $38 \mathrm{~mm}$ ) results in a reduction in bond force in all cases. For embedment lengths of 6 and 12 in. (150 and $305 \mathrm{~mm}$ ) (as represented by the best-fit lines), the $1-1 / 2$ in./3 in. $(38 \mathrm{~mm} /$ $75 \mathrm{~mm}$ ) cover strength ratios are, respectively, 0.86 and 0.99 for uncoated (M) cast-in-place bars, 0.81 and 0.85 for epoxycoated (E) cast-in-place bars, 0.86 and 0.91 for TCB-grouted bars, and 0.74 and 0.78 for TCA-grouted bars. In none of these cases, however, is bond strength as sensitive to cover as it is for the splice strength of cast-in-place bars. ${ }^{17}$

\section{Horizontal bars}

Top-cast and bottom-cast No. 5 and No. 8 bars with 3 in. $(75 \mathrm{~mm})$ cover were used to evaluate the bond strength of

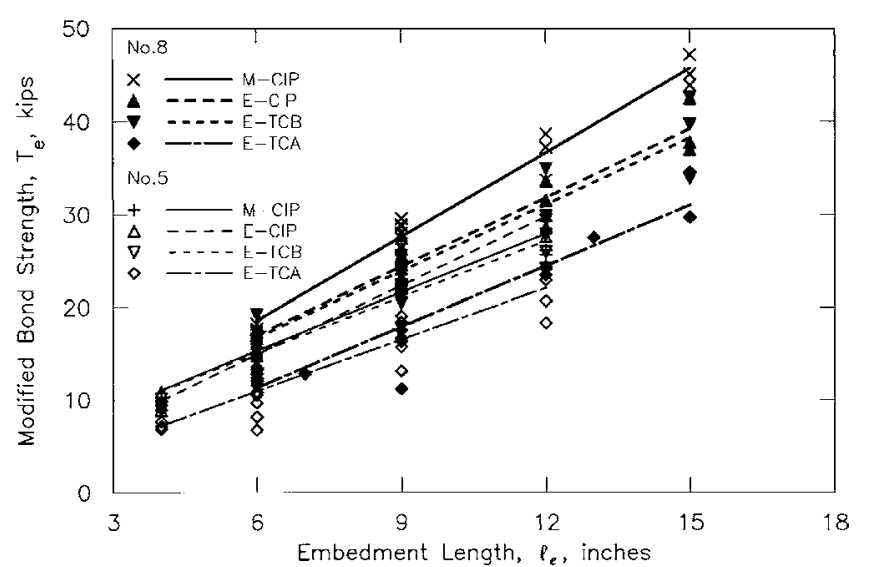

Fig. 4-Modified bond strength $\mathrm{T}_{\mathrm{e}}$ versus embedment length $\ell_{\mathrm{e}}$ for vertical No. 5 and 8 (16 and $25 \mathrm{~mm}$ ) bars with 3 in. cover $(1 \mathrm{kip}=4.45 \mathrm{kN}$; $1 \mathrm{in} .=25.4 \mathrm{~mm})$.

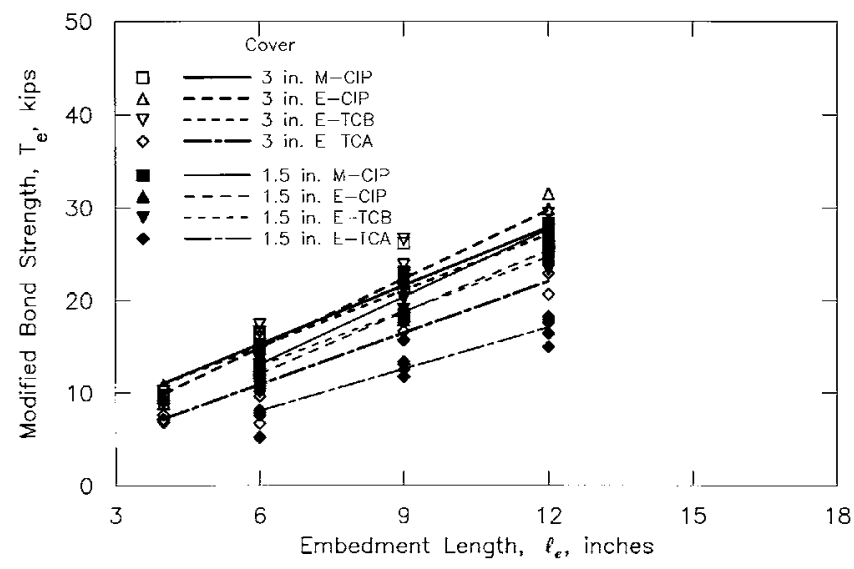

Fig. 5-Modified bond strength $\mathrm{T}_{\mathrm{e}}$ versus embedment length $\ell_{\mathrm{e}}$ for vertical No. 5 (16 mm) bars with 1-1/2 and 3 in. cover $(1 \mathrm{kip}=4.45 \mathrm{kN}$; 1 in. $=25.4 \mathrm{~mm})$.

bars grouted in horizontal holes. The No. 8 bars were cast-inplace or anchored in 1-1/4 in. (32 $\mathrm{mm})$ diameter holes with CPA, NSA, and TCA grouts, while the No. 5 bars were castin-place or anchored in 7/8 in. (22 mm) holes with CPA and TCA grouts. All bars were epoxy-coated. The results are illustrated in Fig. 6 for the top-cast bars.

Fig. 6 shows that the cast-in-place and CPA-grouted No. 8 (25 mm) bars have similar strengths. In fact, the CPA bars have higher strengths for embedment lengths of 9 in. (230 $\mathrm{mm})$ or more. The No. $8(25 \mathrm{~mm})$ NSA and TCA-grouted bars exhibit significantly lower strengths, with the NSA-grouted bars exhibiting higher strengths than the TCA-grouted bars. For $\ell_{e}=6$ and 15 in. (150 and $380 \mathrm{~mm}$ ), the grouted-to-castin-place strength ratios are, respectively, 0.96 and 1.05 for CPA, 0.70 and 0.92 for NSA, and 0.65 and 0.84 for TCA.

For No. 5 (16 mm) bars, Fig. 6 shows that the cast-in-place bars are significantly stronger than the TCA-grouted bars, which are stronger than the CPA-grouted bars. The CPAgrouted bars actually decrease in strength with increasing $\ell_{e}$. As with vertically placed bars, horizontal No. 5 bars provide lower bond strengths than horizontal No. 8 bars with the same embedment length and anchoring method. 


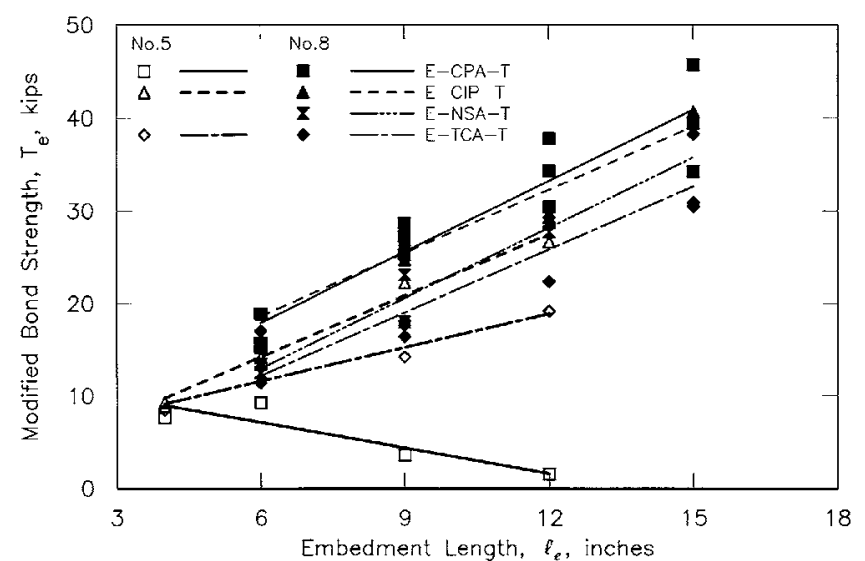

Fig. 6-Modified bond strength $\mathrm{T}_{\mathrm{e}}$ versus embedment length $\ell_{\mathrm{e}}$ for top-cast horizontal No. 5 and $8(16$ and $25 \mathrm{~mm})$ bars with 3 in. cover $(1 \mathrm{kip}=4.45 \mathrm{kN} ; 1 \mathrm{in} .=25.4 \mathrm{~mm})$.

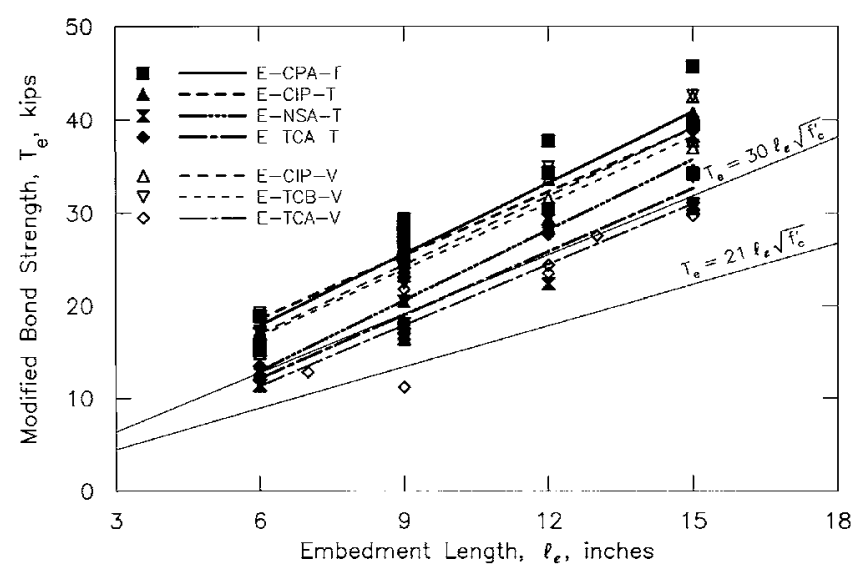

Fig. 7-Modified bond strength $\mathrm{T}_{\mathrm{e}}$ versus embedment length $\ell_{\mathrm{e}}$ for vertical and top-cast horizontal No. $8(25 \mathrm{~mm})$ bars with 3 in. cover and expressions defining minimum strength class requirements for $\mathrm{f}_{\mathrm{c}}{ }^{\prime}=5000$ psi $(1 \mathrm{kip}=4.45 \mathrm{kN} ; 1$ in. $=25.4 \mathrm{~mm} ; 1000 \mathrm{psi}=6.89 \mathrm{MPa}$ ).

The behavior of the CPA-grouted No. 5 (16 mm) bars (Fig. 6) represents a significant departure from the behavior observed for any other bars. The CPA No. 5 bars exhibit nearly equal strengths for $\ell_{e}=4$ and 6 in. $(100$ and $150 \mathrm{~mm})$, but progressively lower strengths for $\ell_{e}=9$ and 12 in. (230 and $305 \mathrm{~mm})$. The strength for $\ell_{e}=6 \mathrm{in}$. $(150 \mathrm{~mm})$ is below that observed for the vertically placed No. 5 bars anchored with CPA grout (Table 1). The low strength (at all embedment lengths) may be due to the fact that the 7/8 in. $(22 \mathrm{~mm})$ hole diameter used for the CPA bars is greater than the value of 13/16 in. $(21 \mathrm{~mm})$ recommended by the manufacturer and used for the vertical bars. Since CPA grout contains microaggregate particles, the size of which may play an important role in interlock as bond failure occurs, the greater gap between the reinforcing bar and the wall of the hole may have resulted in the lower capacity. This was not a factor for the No. $8(25 \mathrm{~mm})$ bars, since the hole diameter used for the No. 8 bars, $1-1 / 4$ in. ( $32 \mathrm{~mm}$ ), was that recommended by the manufacturer. For the No. 5 bars with $\ell_{e}=4$ and 12 in. (100 and $305 \mathrm{~mm}$ ), the grouted-to-cast-in-place strength ratios are, respectively, 0.94 and 0.69 for TCA and 0.92 and 0.05 for CPA based on the best-fit lines. The trends observed for top-cast bars were also exhibited by the bottom-cast bars. ${ }^{1}$

Top-bar effect-The bottom-cast No. 8 bars in this study exhibited higher bond strengths than the corresponding topcast bars for all values of $\ell_{e}$. The higher capacity is likely due to the higher quality of the concrete at the bottom of the placement. Overall, the top-bar effect (ratio of bond strengths of bottom-cast bars to top-cast bars) based on the best-fit lines ranges from 1.08 to 1.10 for cast-in-place No. 8 (25-mm) bars, from 1.00 to 1.06 for cast-in-place No. $5(16 \mathrm{~mm})$ bars, from 1.06 to 1.15 for CPA-grouted No. 8 bars, from 1.06 to 1.08 for NSA-grouted No. 8 bars, from 1.03 to 1.06 for TCA-grouted No. 8 bars, and from 0.96 to 1.02 for TCAgrouted No. 5 bars [the top-bar effect for the CPA-grouted No. 5 bars, which ranges from 0.85 to 3.13 , is not of much practical interest, but is reported for completeness]. These values compare to top-bar factors of 1.3 and 1.4 used by the ACI Building Code $^{20}$ and AASHTO Bridge Specifications, ${ }^{21}$ respectively.

Comparison with vertically anchored bars-Fig. 7 compares the bond strengths for vertical and top-cast horizontal No. $8(25 \mathrm{~mm})$ bars and demonstrates that for the castin-place (CIP) and TCA-anchored No. 8 bars the top-cast horizontal bars, on average, provide slightly higher strengths than the vertical bars (maximum difference in best-fit lines = 1.7 kips $[7.6 \mathrm{kN}]$ in both cases). Comparisons for the CPA and NSA-grouted bars must be made based on a single embedded length, since vertically anchored No. 8 bars using these grouts were tested only with 9 in. $(230 \mathrm{~mm})$ embedment lengths. In these cases, bond strength is more sensitive to bar orientation. For $\ell_{e}=9$ in. $(230 \mathrm{~mm})$, the CPA and NSAgrouted top-cast horizontal bars have lower average strengths than the corresponding vertical bars, 25.6 versus 28.2 kips (114 versus $125 \mathrm{kN}$ ) for the CPA-grouted bars and 20.6 versus 23.2 kips (92 versus $103 \mathrm{kN}$ ) for the NSA-grouted bars.

As shown in Fig. 8, the horizontal No. 5 (16 mm) cast-inplace and TCA-grouted bars have lower strengths than the corresponding vertical bars for most values of $\ell_{e}$. The low strength of the top-cast horizontal CPA-grouted bars was discussed earlier in the paper.

\section{Sloped bars}

Grouted reinforcing bars are often inserted at an angle rather than perpendicular to the surface. To evaluate the effect of bar slope on bond strength, 15 No. $5(16 \mathrm{~mm})$ bars were inserted at a slope-six with a slope of $1: 3$ and nine with a slope of 1:6 [Fig. 1(a)]. The bars were oriented so that the cover increased with increasing embedment.

The sloped bars exhibited strengths that were equal to or greater than the strengths of bars that were placed with uniform cover equal to the minimum cover on the sloped bar in all but two tests (two NSA-grouted bars with $\ell_{e}=6$ in. [150 mm] and a 1:6 slope). Considering the fact that the preponderance of that data indicates improved performance, it appears that it would be safe to consider sloped reinforcement as equivalent to reinforcement placed with a constant cover equal to the minimum cover on the sloped bar. 


\section{Concrete strength}

One test group was used to provide some insight into the effect of concrete strength on the bond capacity of anchored bars. The group consisted of nine vertically anchored No. 5 bars, with 6-in. embedment. Three bars each were anchored with NSA, CPA, and TCA grouts. The concrete had a strength of $2700 \mathrm{psi}(18.6 \mathrm{MPa})$ at the time of the test, producing bond strengths significantly below those provided by bars with nominal concrete strengths of $5000 \mathrm{psi}(34.5 \mathrm{MPa})$. However, when the bond strengths are multiplied by $\left(5000 / f_{c}^{\prime}\right)^{1 / 2}\left[f_{c}^{\prime}\right.$ in psi], the modified bond strengths overlap the test results provided by the vertically anchored No. 5 bars in 5000 psi (34.5 MPa) concrete. For NSA grout, the modified bond strengths range from 13.1 to $15.2 \mathrm{kips}$ ( 58 to $68 \mathrm{kN}$ ), compared to a range of 10.9 to 17.4 kips ( 48 to $77 \mathrm{kN}$ ) for the earlier $(5000 \mathrm{psi}[34.5 \mathrm{MPa}$ ] concrete) tests at a 6 in. $(150 \mathrm{~mm})$ embedment; for CPA grout, modified bond strengths range from 7.0 to $13.5 \mathrm{kips}$ ( 31 to $60 \mathrm{kN}$ ), compared to 10.0 to $18.5 \mathrm{kips}$ (44 to $82 \mathrm{MPa}$ ) for earlier tests; and for TCA grout, modified bond strengths range from 8.7 to 12.3 kips ( 39 to $55 \mathrm{kN}$ ), compared to 6.8 to 15.4 kips ( 30 to $69 \mathrm{kN}$ ) for earlier tests.

This limited comparison suggests that using the square root of the compressive strength is a reasonable way to account for the effect of concrete strength on the capacity of grouted reinforcing bars. The limited nature of the data also suggests that additional tests would be worthwhile.

\section{RECOMMENDATIONS FOR DESIGN AND CONSTRUCTION}

The design procedures that follow recognize that: 1) different grouts exhibit different strengths; 2) individual grouts may provide different strengths when used to anchor bars in horizontal and vertical holes; 3) the bond strength provided by grouted bars drops with decreasing cover; and 4) the bond strength of a sloped bar can be conservatively represented by the strength of a bar with a constant concrete cover equal to the minimum cover on the sloped bar. Although not evaluated in this study, it is assumed that the bond strength of grouted bars will drop with decreasing center-to-center spacing, as occurs for cast-in-place bars. ${ }^{16,17}$

The approach defines three strength classes of grout: Strength Class A, Strength Class B, and a Special Strength Class. Strength Classes A and B are based on minimum strength requirements, while the Special Strength Class is provided to allow for the use of the actual test results.

\section{Definitions}

Strength class-A category of grout based on the bond strength it provides for anchoring embedded reinforcement. The strength class of a grout should be established separately, and need not be the same, for horizontal and vertical bar installations, since it is observed that grouts can perform differently based on bar orientation. The procedures for establishing the strength class should match those used in this study and are spelled out in ASTM format in Reference 1 and summarized below.

Strength Class A Grout-A grout that provides a minimum average bond strength $T_{e}=A_{b} f_{s}=30 \ell_{e} \sqrt{f_{c}^{\prime}}$ for $\ell_{e}$ $=9 d_{b}$ and $\ell_{e}=15 d_{b}$, in which $T_{e}=$ tensile force in grouted

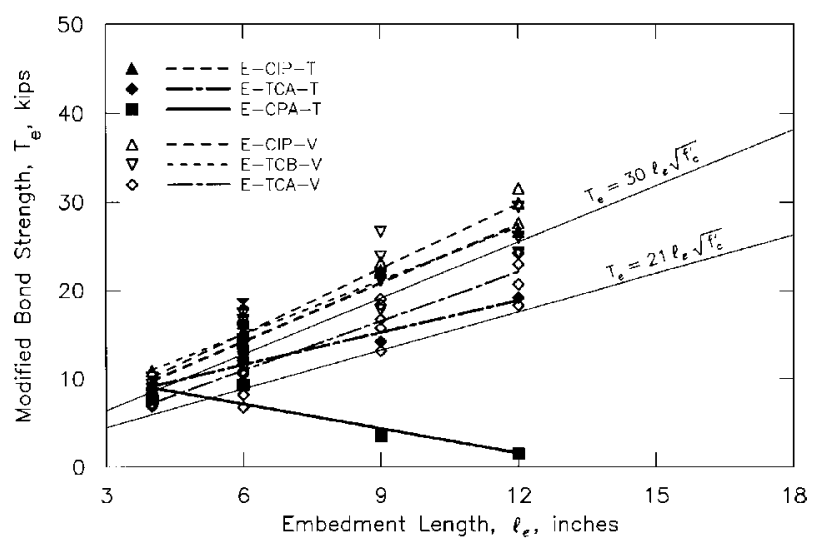

Fig. 8-Modified bond strength $\mathrm{T}_{\mathrm{e}}$ versus embedment length $\ell_{\mathrm{e}}$ for vertical and top-cast horizontal No. $5(16 \mathrm{~mm})$ bars with 3 in. cover and expressions defining minimum strength class requirements for $\mathrm{f}_{\mathrm{c}}{ }^{\prime}=5000$ psi $(1 \mathrm{kip}=4.45 \mathrm{kN} ; 1$ in. $=25.4 \mathrm{~mm} ; 1000 \mathrm{psi}=6.89 \mathrm{MPa}$ ).

reinforcement at bond failure, $\mathrm{lb} ; A_{b}=$ area of an individual bar, in. ${ }^{2} ; f_{s}=$ tensile stress in reinforcement, psi; $\ell_{e}=$ embedded length of grouted reinforcement, in.; $\sqrt{f_{c}^{\prime}}=$ square root of concrete compressive strength, psi.

Strength Class B Grout-A grout that provides a minimum average bond strength $=70$ percent of that required of a Strength Class A grout.

Special Strength Class Grout-A grout that provides a minimum average bond strength $=T_{e}=A_{b} f_{s}=\gamma \ell_{e} \sqrt{f_{c}^{\prime}}$ for $\ell_{e}=$ $9 d_{b}$ and $\ell_{e}=15 d_{b}$, in which $\gamma=$ factor obtained in evaluating grout strength $=T_{e}(a v g) / \ell_{e} \sqrt{f_{c}^{\prime}}$.

Grout Strength Classes A and B were established using the test results for top-cast horizontal and vertical bars. The specific strength requirements defining the classes were selected primarily based on the strength properties of grouted No. 5 bars, since these provide lower bond strengths than larger bars with the same embedment length.

Two primary strength classes, A and B, were selected to both allow economical use of the highest strength grouts without preventing the use of lower strength grouts that may have desirable construction properties, such as rapid curing, but require longer embedment lengths. The Special Strength Class allows any grout to be used based on its actual performance. The strength of a Special Strength Class grout may be above or below that of Strength Classes A or B. The proposed requirements for evaluating the strength of a grout ${ }^{1}$ require a minimum of three tests each at embedment lengths equal to 9 and 15 bar diameters, and a cover of 3 in. $(75 \mathrm{~mm})$. General qualification as a Strength Class A, Strength Class B, or Special Strength Class grout would require the use of No. 5 bars. However, a Special Strength Class grout could be qualified using a bar size other than No. 5, but the application of that Special Strength Class would be limited to the bar size used in the test.

The requirements for Strength Class A and Strength Class $\mathrm{B}$ are compared with the test results for vertical and top-cast horizontal No. 5 and No. 8 (16- and 25-mm) bars in Fig. 8 and 7, respectively. As illustrated in Fig. 8, TCB grout in vertical holes would qualify as a Strength Class A grout, while TCA in both vertical and top-cast horizontal holes 
would qualify as a Strength Class B grout. CPA grout, as applied with a single capsule and oversize holes (not in accordance with the manufacturer's recommendations), would not meet the requirements of a standard strength class grout.

The No. 8 bars provide higher strengths than the No. 5 bars, as illustrated in Fig. 7. CPA grout and NSA grout in top-cast horizontal holes and TCB grout in vertical holes meet the requirements of a Strength Class A grout, while TCA grout in both horizontal top-cast and vertical holes provides strengths that place it in the upper range of Class B grouts. Under these proposed design procedures, the engineer would have the option of using the lower strengths obtained with the No. 5 bars to establish the strength class or treating the grouts used with the No. 8 bars as belonging to a Special Strength Class to take advantage of the higher strengths obtained with the larger bars.

\section{Design}

Strength reduction factors

1. Steel yield strength: $\phi=0.90$

2. Bond strength: $\phi=0.65$

A strength reduction factor of 0.90 is commonly used when strength is governed by tensile yielding of reinforcing steel. $^{20-22}$ A strength reduction factor of 0.65 is commonly used when strength is governed by the tensile strength of concrete or the anchorage provided by a grout. ${ }^{5,22}$

Design tensile strength-The design tensile strength of grouted reinforcement $\phi T_{n}$ must exceed the factored tensile force in the reinforcement. $\phi T_{n}$ is equal to the smaller of the design tensile force based on the yield strength of the bar, given by Eq. (1), and the design tensile force based on the bond strength of the grout, given by Eq. (2), (3), or (4)

$$
\phi T_{n}=\phi A_{b} f_{y}=0.9 A_{b} f_{y}
$$

in which $f_{y}=$ specified yield strength of reinforcement, psi.

Strength Class A Grout

$$
\phi T_{n}=\phi 30 l_{e} \sqrt{f_{c}^{\prime}}=19.5 l_{e} \sqrt{f_{c}^{\prime}}
$$

Strength Class B Grout

$$
\phi T_{n}=\phi 21 l_{e} \sqrt{f_{c}^{\prime}}=13.7 l_{e} \sqrt{f_{c}^{\prime}}
$$

Special Strength Class Grout

$$
\phi T_{n}=\phi \gamma l_{e} \sqrt{f_{c}^{\prime}}=0.65 \gamma l_{e} \sqrt{f_{c}^{\prime}}
$$

Eq. (2) and (3) produce predicted strengths equal to 78 and 55 percent, respectively, of the strength that would be calculated for cast-in-place bars using the expression for basic development length in the 1989 ACI Building Code ${ }^{20}$ and the 1992 AASHTO Bridge Specifications. ${ }^{21}$

Modification factors based on cover and bar spacingFor bars with covers less than 3 in. (75 mm) or clear spacings less than 6 in. $(150 \mathrm{~mm})$, the value of design strength $\phi T_{n}$, calculated using Eq. (2), (3), or (4), should be modified by a factor of 0.85 for bars anchored with a grout that meets the requirements of a Strength Class A grout and 0.75 for bars anchored with grouts that do not. These requirements are based on observations made earlier in the paper indicating that the bond strengths of bars anchored with Strength Class $\mathrm{B}$ grouts are more sensitive to low covers than the bond strengths of bars anchored with Strength Class A grouts. Both modification factors are less severe than the corresponding factors in ACI 318-89, ${ }^{20}$ reflecting the lower cover sensitivity of bars that are grouted compared to bars that are spliced or developed. Covers less than 1-1/2 in. (38 mm) and clear spacings less than 3 in. $(75 \mathrm{~mm}$ ) should not be permitted unless justified by tests. For bars with cover that changes along the embedded length, cover should be interpreted as minimum cover.

\section{Construction requirements}

The principal construction considerations are hole size and cleanliness. The only case in which hole diameter appears to affect strength is when capsules are used. To cover this case, construction requirements should require the use of "hole diameters that have been demonstrated to provide adequate strength."

To insure adequate surface properties, holes should be vacuumed (as with a shop vacuum) after drilling, brushed with a fiber brush, and then blown out with compressed air (filtered for oil and water). If another less stringent cleaning method is used, the grout bond strength should be qualified using the alternate cleaning method.

\section{CONCLUSIONS}

The following conclusions are based on the tests and evaluations presented in this paper.

1. For the techniques evaluated in this study, the bond strength of grouted reinforcing bars is not highly sensitive to differences in hole preparation method. Drilling methods that do not damage the surrounding concrete and most holecleaning methods are satisfactory for most grouts. Grouts that tend to exhibit a bond failure at the interface between grout and concrete (IGC) may provide higher strengths with more thorough cleaning methods. The vacuum drilling procedure appears to provide the best strength for grouts that exhibit IGC failures. However, this method is not required, nor does it give the highest strength for most other grout installations. Vacuuming, followed by cleaning with a fiber bottle brush and compressed air, is recommended.

2. There can be significant differences in grout strength. Grouts that provide a strong bond at the grout-concrete interface provide higher bond strengths than grouts that undergo failure at the grout-concrete interface.

3. The bond strength provided by most grouts is not sensitive to the hole diameter. However, bond strength may be severely decreased for bars anchored with capsules if the hole diameter is larger than recommended by the manufacturer.

4. Bond strength increases with increasing embedment length, bar size, and cover. The bond strength of both castin-place and grouted reinforcing bars subjected to tension at the surface of concrete appears to be less sensitive to cover 
than is the strength of cast-in-place spliced reinforcement within reinforced concrete members.

5. Cast-in-place epoxy-coated reinforcement provides a lower bond strength than cast-in-place uncoated reinforcement. Grouted epoxy-coated reinforcement and grouted uncoated reinforcement provide similar bond strengths.

6. Grouted vertically anchored bars and grouted top-cast horizontally anchored bars provide similar strengths for some grouts and different strengths for other grouts. Therefore, it is recommended that grouts be qualified separately for anchorage at each orientation. Grouted bottom-cast horizontal reinforcement provides a higher bond strength than grouted top-cast reinforcement.

7. The bond strength of a sloped bar can be conservatively represented by the bond strength of a bar with a constant concrete cover equal to the minimum cover on the sloped bar.

8 . For the grouts tested, bond strength increases approximately with the square root of concrete compressive strength.

\section{ACKNOWLEDGMENTS}

Funding for this research was provided by the Kansas Department of Transportation under K-TRAN Project No. KU-91-2. Drilling equipment was supplied by the Hilti, Inc., and the Kansas Department of Transportation. Grouting materials were supplied by Carter-Waters Corp., Cormix Construction Chemicals, Hilti, Inc., and Master Builders, Inc. Reinforcing steel was supplied by Chaparral Steel Co. and Structural Metals, Inc. The epoxy coating was applied by ABC Coating Co., Inc. Form release agent, curing compound, and mounting hardware were supplied by Richmond Screw Anchor Co. Thanks are due to Jun Zuo, graduate research assistant, who participated in much of the experimental work on the project, as well as preparing figures for this paper.

\begin{tabular}{|c|c|}
\hline & NOTATION \\
\hline A & $=$ air cleaning method \\
\hline$A_{b}$ & $=$ area of individual bar, in. ${ }^{2}$ \\
\hline B & $=$ bottom-cast horizontal bar \\
\hline BA & $=$ brush with air-cleaning method \\
\hline BW & $=$ brush with water-cleaning method \\
\hline CIP & $=$ cast-in-place \\
\hline $\mathrm{CPA}, \mathrm{CPB}$ & $=$ Capsule A, Capsule B \\
\hline E & $=$ epoxy-coated \\
\hline$f_{c}^{\prime}$ & $=$ compressive strength of concrete, $\mathrm{psi}$ \\
\hline$f_{s}$ & $=$ tensile stress in reinforcement, psi \\
\hline $\mathrm{H}$ & $=$ horizontal bar \\
\hline IGC & $=$ failure at interface between grout and concrete \\
\hline$\ell_{e}$ & $=$ embedded length of grouted reinforcement, in. \\
\hline M & $=$ mill scale (uncoated) \\
\hline NSA, NSB & $=$ Nonshrink Grout A, Nonshrink Grout $\mathrm{B}$ \\
\hline $\mathrm{T}$ & $=$ top-cast horizontal bar \\
\hline TCA, TCB & $=$ stiff two-component Grout A, fluid two-component Grout $\mathrm{B}$ \\
\hline$T_{e}$ & $\begin{array}{l}=\text { bond strength of grouted reinforcement }=\text { maximum ten- } \\
\text { sile force attained during a test, } \mathrm{lb}\end{array}$ \\
\hline$T_{n}$ & $=$ nominal tensile force in grouted reinforcement, $\mathrm{lb}$ \\
\hline$V$ & $=$ vacuum-drilled or vertical bar \\
\hline 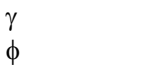 & $\begin{array}{l}=\text { factor obtained in evaluating grout strength }=T_{e}(\mathrm{avg}) / \ell_{e} \sqrt{f_{c}{ }^{\prime}} \\
=\text { strength reduction factor }\end{array}$ \\
\hline
\end{tabular}

\section{REFERENCES}

1. Darwin, D., and Salamizavaregh, S., "Bond Strength of Grouted Reinforcing Bars," SM Report No. 32, University of Kansas Center for Research, Lawrence, Kansas, Oct. 1993, 139 pp.
2. Stowe, R. L., "Pullout Resistance of Reinforcing Bars Embedded in Hardened Concrete," Miscellaneous Paper C-74-2, U. S. Army Engineer Waterways Experiment Station, Concrete Laboratory, Vicksburg, MS, June 1974, 33 pp.

3. Cannon, R. W.; Godfrey, D. A.; and Moreadith, F. L., "Guide to the Design of Anchor Bolts and Other Steel Embedments," and "Commentary on Guide to the Design of Anchor Bolts and Other Steel Embedments," Concrete International, V. 3, No. 7, July 1981, pp. 28-41.

4. Cook, R. A.; Collins, D. M.; Klingner, R. E.; and Polyzois, D., "LoadDeflection Behavior of Cast-in-Place and Retrofit Anchors," ACI Structural Journal, V. 89, No. 6, Nov.-Dec. 1992, pp. 639-649.

5. Cook, R. A.; Doerr, G. T.; and Klingner, R. E., "Bond Stress Model for Design of Adhesive Anchors," ACI Structural Journal, V. 90, No. 5, Sept.-Oct. 1993, pp. 514-524.

6. Choi, O. C.; Hadje-Ghaffari, H.; Darwin, D.; and McCabe, S. L., "Bond of Epoxy-Coated Reinforcement to Concrete: Bar Parameters," SL Report 90-1, University of Kansas Center for Research, Lawrence, KS, Jan. 1990, 43 pp.

7. Choi, O. C.; Hadje-Ghaffari, H.; Darwin, D.; and McCabe, S. L., "Bond of Epoxy-Coated Reinforcement: Bar Parameters," ACI Materials Journal, V. 88, No. 2, Mar.-Apr. 1991, pp. 207-217.

8. ASTM A 615-90, "Standard Specification for Deformed and Plain Billet-Steel Bars for Concrete Reinforcement," ASTM International, Philadelphia, PA, 1990, 4 pp.

9. ASTM A 775/A775M-91b, "Standard Specification for Epoxy-Coated Reinforcing Steel Bars," American Society for Testing and Materials, Philadelphia, PA, 6 pp.

10. Stratton, F. W.; Alexander, R.; and Nolting, W., "Cracked Structural Concrete Repair through Epoxy Injection and Reinforcing Bar InsertionFinal Report," Report No. FHWA-KS-RD.78-3, Kansas Department of Transportation, Topeka, KS, Nov. 1978, 56 pp.

11. Stratton, F. W.; Alexander, R.; and Nolting, W., "Development and Implementation of Concrete Girder Repair by Postreinforcement," Report No. FHWA-KS-RD.82-1, Kansas Department of Transportation, Topeka, May 1982, $31 \mathrm{pp}$.

12. Menzel, C. A., "Effect of Settlement of Concrete on Results of Pullout Tests," Research Department Bulletin 41, Research and Development Laboratories of the Portland Cement Association, Nov. 1952, 49 pp.

13. Ferguson, P. M., and Thompson, J. N., "Development Length of High-Strength Reinforcing Bars in Bond," ACI JouRnAL, Proceedings V. 59, No. 7, July 1962, pp. 887-922.

14. Johnston, D. W., and Zia, P., "Bond Characteristics of Epoxy-Coated Reinforcing Bars," Report No. FHWA-NC-82-002, Center for Transportation Engineering Studies, Civil Engineering Department, North Carolina State University, Raleigh, NC, 1982, 163 pp.

15. Hester, C. J.; Salamizavaregh, S.; Darwin, D.; and McCabe, S. L., "Bond of Epoxy-Coated Reinforcement: Splices," ACI Structural Journal, V. 90, No. 1, Jan.-Feb. 1993, pp. 89-102.

16. Orangun, C. O.; Jirsa, J. O.; and Breen, J. E., "Re-Evaluation of Test Data on Development Length and Splices," ACI JouRnaL, Proceedings V. 74, No. 3, Mar. 1977, pp. 114-122.

17. Darwin, D.; McCabe, S. L.; Idun, E. K.; and Schoenekase, S. P., "Development Length Criteria: Bars Not Confined by Transverse Reinforcement," ACI Structural Journal, V. 89, No. 6, Nov.-Dec. 1992, pp. 709-720.

18. "Standard Specifications for State Road and Bridge Construction," Kansas Department of Transportation, Topeka, KS, 1990, 1154 pp.

19. ACI Committee 345, "Guide for Widening Highway Bridges (ACI 345.2R)," ACI Structural Journal, V. 89, No. 4, July-Aug. 1992, pp. 451-466.

20. ACI Committee 318, "Building Code Requirements for Reinforced Concrete (ACI 318-99) and Commentary (318R-89)," American Concrete Institute, Detroit, 1989, 353 pp.

21. AASHTO Highway Subcommittee on Bridges and Structures, Standard Specifications for Highway Bridges, 15th Edition, American Association of State Highway and Transportation Officials, Washington, D.C., 1992, 686 pp.

22. ACI Committee 318, "Building Code Requirements for Structural Plain Concrete and Commentary (ACI 318.1-89/ACI 318.1R-89)," American Concrete Institute, Detroit, 1989, 14 pp. 
93-S45

Supplement to:

\section{ACI STRUCTURAL JOURNAL}

Appendix to:

Title no. 93-S45, ACI Structural Journal, V. 93, No. 3, July-Aug. 1996, pp. 486-495

"Bond Strength of Grouted Reinforcing Bars" by D. Darwin and S.S. Zavaregh 


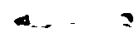

\section{APPENDIX A}

to

BOND STRENGTH OF GROUTED REINFORCING BARS

by

David Darwin and Shahin S. Zavaregh

\section{TEST DATA}


Table A.1: Test Bar Data

\begin{tabular}{|c|c|c|c|c|c|c|}
\hline $\begin{array}{c}\text { Bar } \\
\text { Size } \\
\text { No. }\end{array}$ & $\begin{array}{c}\text { Def } \\
\text { Pattern }\end{array}$ & $\begin{array}{l}\text { Yield } \\
\text { Strength } \\
\text { (ksi) }\end{array}$ & $\begin{array}{c}\text { Det. } \\
\text { Height } \\
\text { (in.) }\end{array}$ & $\begin{array}{l}\text { Def. } \\
\text { Spacing } \\
\text { (in.) }\end{array}$ & $\begin{array}{l}\text { Def. } \\
\text { Gap } \\
\text { (in.) }\end{array}$ & $\begin{array}{r}\text { Def. } \\
\text { Angle } \\
\text { (deg.) }\end{array}$ \\
\hline $5^{\circ}$ & $C$ & 72.3 & 0.041 & 0.413 & 0.116 & 60 \\
\hline $5 *$ & C & 72.3 & 0.040 & 0.413 & 0.140 & 60 \\
\hline $5^{\circ \cdots 0}$ & C & 65.5 & 0.041 & 0.403 & 0.182 & 60 \\
\hline 5 & $\mathbf{S}$ & 70.6 & 0.031 & 0.423 & 0.159 & 90 \\
\hline $8^{000}$ & C & 69.0 & 0.062 & 0.654 & 0.165 & 60 \\
\hline $8+$ & C & 67.6 & 0.064 & 0.590 & 0.285 & 60 \\
\hline $8+$ & C & +++ & 0.062 & 0.656 & 0.195 & 60 \\
\hline
\end{tabular}

- Used for epoxy-coated (E) bars; except as noted

- Used for uncoated (mill scale surface a M) bars, except as noted

-. Used for uncoated $(M)$ bars in Groups 15-17, 19

- Used for uncoated (M) bars in Groups 12-14

* Used tor horizontal bars in Group 24

- Yleld strength is greater than $70.0 \mathrm{ksi}$

Table A.2: Concrete Mixture Proportions (Cubic Yard Batch Weights)

\begin{tabular}{lcccccc}
\hline Group & $\begin{array}{c}\text { Nominal } \\
\text { Strength } \\
\text { (psi) }\end{array}$ & W/C ratio & Cement & Water & $\begin{array}{c}\text { Aggregate } \\
\text { Fine+ Coarse } \\
\text { (lb) }\end{array}$ \\
\hline \hline & & (lb) & (lb) & & & \\
1 & 5000 & 0.46 & 520 & 240 & 1525 & 1525 \\
2 & 5000 & 0.42 & 544 & 230 & 1595 & 1595 \\
$4-22,24$ & 5000 & 0.43 & 520 & 225 & 1545 & 1545 \\
23 & 2500 & 0.46 & 496 & 228 & 1508 & 1565 \\
\hline
\end{tabular}

+ Kansas River Sand - Lawrence Sand Co., Lawrence, KS, bulk specific gravity $(s s d)=262$, absorption $=0.5 \%$, fineness modulus $=3.0$.

\# Crushed limestone - Fogei's Quary, Ottawa, KS, bulk specific gravity (sso) = 2.57 absorption $=3.0 \%$, nominal maximum size $=3 / 4$ in., unit weight $=90.5$ bror. 
Table A.3: Concrete Properties

\begin{tabular}{|c|c|c|c|c|c|c|}
\hline Group & Slump & $\begin{array}{l}\text { Concrete } \\
\text { Temperature } \\
(\boldsymbol{P}\end{array}$ & $\begin{array}{l}\text { Age at } \\
\text { Test } \\
\text { (dans). }\end{array}$ & $\begin{array}{l}\text { Grout Age } \\
\text { at Test } \\
\text { (dans) }\end{array}$ & $\begin{array}{c}\text { Air } \\
\text { Content } \\
\%\end{array}$ & $\begin{array}{l}\text { Average Compressive } \\
\text { Strength } \\
\text { (p) }\end{array}$ \\
\hline 1 & $31 / 2$ & 78 & 69 & $3-4$ & • & 5340 \\
\hline \multirow[t]{2}{*}{2} & 4 & 78 & 41 & $5-6$ & 3.1 & 5350 \\
\hline & & & 42 & & & 5500 \\
\hline 4 & 2 & 72 & 78 & $3-4$ & 1.9 & 5460 \\
\hline 5 & $21 / 2$ & 74 & 56 & $4 \cdot 5,7$ & 5.6 & 5570 \\
\hline \multirow[t]{2}{*}{6} & 3 & 63 & 33 & 7 & 5.8 & 5250 \\
\hline & & & 34 & 8 & & 5530 \\
\hline 7 & $31 / 2$ & 51 & 16 & 3 & 5.8 & 4460 \\
\hline 8 & 3 & 52 & 24 & 3 & 5.9 & 4790 \\
\hline 9 & $31 / 4$ & 45 & 27 & 3 & 6.4 & 5360 \\
\hline 10 & $31 / 2$ & 52 & 20 & 3 & 5.5 & 4970 \\
\hline 11 & $31 / 2$ & 52 & 31 & 4 & 6.4 & 5230 \\
\hline 12 & $23 / 4$ & 64 & 25 & 3 & 6.2 & 5270 \\
\hline 13 & 3 & 59 & 21 & 3 & 5.2 & 5600 \\
\hline 14 & $45 / 8$ & 60 & 22 & 3 & 6.6 & 4550 \\
\hline \multirow[t]{3}{*}{15} & $13 / 4$ & 62 & 25 & 3 & 5.0 & 5360 \\
\hline & & & 26 & 4 & & 5480 \\
\hline & & & 46 & 24 & & 5870 \\
\hline 16 & $43 / 4$ & 68 & ' 39 & $3-4$ & 6.2 & 4610 \\
\hline 17 & $31 / 4$ & 70 & 27 & 3 & 5.3 & 4980 \\
\hline \multirow[t]{2}{*}{18} & $31 / 4$ & 67 & 35 & 3 & 5.6 & 5400 \\
\hline & & & 45 & 3 & & 5600 \\
\hline \multirow[t]{2}{*}{19} & $61 / 2$ & 68 & 26 & 5 & 6.4 & 3960 \\
\hline & & & 31 & 3 & & 4270 \\
\hline \multirow[t]{2}{*}{20} & $21 / 2$ & 69 & 47 & 3 & 4.9 & 5230 \\
\hline & & & 57 & 3 & & 5490 \\
\hline \multirow[t]{3}{*}{21} & 3 & 66 & 26 & 3 & 5.8 & 4410 \\
\hline & & & 27 & & & 4660 \\
\hline & & & 44 & 3 & & 5270 \\
\hline 22 & $23 / 4$ & 67 & 24 & 3 & 4.8 & 4980 \\
\hline 23 & $43 / 4$ & 62 & 5 & 3 & 6.8 & 2700 \\
\hline \multirow[t]{4}{*}{24} & $31 / 2$ & 59 & 22 & 3 & 5.8 & 4600 \\
\hline & & & 29 & 7 & & 4740 \\
\hline & & & 53 & 31 & & 4980 \\
\hline & & & 53 & 6.7 & & $4980^{\circ}$ \\
\hline
\end{tabular}

- Not measured

- Horizontal Bars 


Grout Symbol:
Manufacturer:
Grout Trade Name
and Description:
Ingredients:

Grout Symbol: Manufacturer:

Appropriate diamoter capsule ( $5 / 8 \times 5$ in. or 1 in. $\times 81 / 4$ in.) was inserted into a predrilled hole. Recommended hole diameter $=13 / 16$ in. for No. 5 bars and $11 / 4$ in. for No. 8 bars. The rebar was inserted in setting tool mounted on a TE-72 Hiti rotary hammer drill. The end of the rebar with a $45^{\circ}$ cut on it was placed on top of the capsule. The drill was switched on, and the rebar was drilled to the bottom of the hole with rotary hammer drill set in the hammer/rotation mode. The curing time varied based on the temperature of the base concrete.

Grout Symbol: Manufacturer:

Ingredients:
Grout Trade Name and Description:

Grout Trade Name
and Description:

CPA

Hit, Inc.

5400 S. 122nd East Avenue

Tulsa, OK 74146

HEA Adhesive Capsule

Vinyl ester resin system packed in sealed glass tubes. Part $A$ is in the outer tube and Part $B$ is in the inner tube.

Part A: Styrene, vinyl ester resin

Part B: Dibenzoyl peroxide, silica sand

\section{CPB}

RAWLPLUG CO., Inc.

\section{P.O.Box 641}

New Rochelle. NY 10802-9978

Chem-Stud Capsule

The Chem-Stud adhesive is packaged in single use (outer \& inner) glass capsules which have premeasured components.

Outer Capsule: Polyester resin, quartz aggregate

Inner Capsule: Benzol peroxide hardening agent

A 5/8 in. capsule was inserted into a predrilled hole. The rebar was inserted in seitting tool mounted on a TE-72 Hiti rotary hammer drill. The end of the rebar with a $45^{\circ}$ cut on it was placed on top of the capsule. The drill was switched on, and the rebar was drilled to the botiom of the hole with rotary hammer drill set in the hammer/rotation mode. The curing time varied based on the temperature of the base concrete.

Grout Symbol: Manufacturer:

Grout Trade Name and Description: Ingredlents:
TCA

Hitt, Inc.

5400 S. 122nd East Avenue

Tulsa, OK 74146

HIT C-100 Adhesive

Material is packed in two tubes joined together. Pan A is located in the larger tube, part B is located in the smaller tube.

Part A: Vinyl ester resin, unsaturated polyester resin styrene, fumed silica, sillca sand

Part B: Dibenzoyl peroxide, fumed silica, paraffin wax, micro hollow balls 
HIT C-100 adhesive was injected into the hole using a Hilti P-2000 manual dispenser. Rebar was rotated by hand during installation to insure proper adhesion between grout and rebar. The gel time and cure time of the grout varied based on the temperature of the base concrete.

$\begin{array}{ll}\text { Grout Symbol: } & \text { TCB } \\ \text { Manufacturer: } & \text { The Carter-Waters Corporation } \\ & 2440 \text { West Pennway } \\ & \text { P. O. Box } 412676 \\ & \text { Kansas City, MO } 64141 \\ \text { Grout Trade Name } & \text { CWC 202, Type I } \\ \text { and Descriptlon: } & \text { A two component 100\% solids, moisture insensitive, multipurpose structural } \\ & \text { epoxy bonding agent. } \\ \text { Ingredients: } & \text { Component A (epoxy resin) - Bisphenol A diglycidyl ether resin Component B - } \\ & \text { Polysulfied polymer, dimethylaminomethylphenol, 2,4,6, - Tri (Dimethyla- } \\ & \text { minomethyl) phenol }\end{array}$

Bonding Agent designed for application temperatures between $68^{\circ} \mathrm{F}$ and $104^{\circ} \mathrm{F}$. Two component bonding agent was mixed in a 2:1 ratio by volume (two parts part A-resin, one part B-curing agent) for three minutes using a paint mixer blade mounted on a $1 / 4 \mathrm{in}$. drill. Blending took place at low speed to avold the formation of alr bubbles in the $\mathrm{mbx}$. The grout, having a honey consistency, was poured directly into the hole, and rebar was rotated by hand during installation to insure proper adhesion. The grout had a pot life of $30 \mathrm{~min}$. and a cure time of 24 hours at $75^{\circ} \mathrm{F}$.

\author{
Grout Symbol: $\quad$ NSA: \\ Manufacturer: $\quad$ Cormix Construction Chemicals \\ P. O. Box 190970 \\ Dallas, TX 75219-0970 \\ Grout Trade Name Non-shrink Supreme Grout. A non-metallic grout, packaged in 55 lb. \\ and Description: poly-lined bags. \\ Ingredients: $\quad$ Silica aggregates, cements, a shrinkage compensating system, and plasticizing \\ agents.
}

The non-shrink grout had a water requirement of $11 / 4-11 / 2$ gal. per $55 \mathrm{lb}$. bag for a fluid state and a yield of $1 / 2 \mathrm{ft}^{3}$ per bag. For fluid consistency, $3 / 4$ of the required water was placed in the container, grout was added slowly while mixing using the drill mounted mixer blade to the point of stalling the mixer. Grout was mixed to a doughy state until all dry material was thoroughly wet. After all lumps had disappeared, the remaining water was added. Mixing continued for a total of 3-5 min. or until a uniform consistency was achleved.

Since small batches were mixed at each placement, grout and water required were carefully measured based on $11 / 2$ gal. per bag requirement. To avoid air pockets and insure complete filling of the hole, the grout was placed from one side of the hole only. Rebar was rotated by hand during installation to insure proper adhesion between grout and rebar. Care was exercised not to overwork the grout in order to avoid segregation or bleeding. Exposed grout surfaces around the rebar were sealed with duct tape for a minimum of 3 days. Working time was approximately 20 min. Setting time was approximately 25-30 min. 
$\begin{array}{ll}\text { Grout Symbol: } & \text { NSB } \\ \text { Manufacturer: } & \begin{array}{l}\text { Master Builders, Inc. } \\ 23700 \text { Chagrin Boulevard } \\ \text { Cleveland, Ohio 44122-5554 } \\ \text { MASTERFLOW } 814 \text { Cable Grout }\end{array} \\ \text { Grout Trade Name } & \begin{array}{l}\text { A one component cement-based grout packaged in } 55 \text { lb moisture-resistant } \\ \text { and Description: }\end{array} \\ \text { bags. } \\ \text { Ingredients: } & \begin{array}{l}\text { Portland Cement and other cementtuous materials and materials that protect } \\ \text { against stress corrosion and hold to a minimum all components including chlo- } \\ \text { rides and sulfides. }\end{array}\end{array}$

Grout had a 2.55 gal. water requirement per $55 \mathrm{lb}$. bag. producing approximately $0.65 \mathrm{ft}^{3}$ of fluid grout. Required water and grout were carefully measured. Water was placed in a container. With the drill mounted mixer blade operating, grout was added steadily and mixed for 2-3 minutes until the grout was uniform and essentially free of lumps. To avoid air pockets and insure complete filling of the hole, the grout was placed from one side of the hole only. Rebar was rotated by hand during installation to insure proper adhesion between grout and rebar. Care was exercised not to ovenwork the grout in order to avold segregation or bleeding. Exposed surfaces were moist cured for 24 hours and sealed thereafter for a minimum of 3 days.

"Horizontal Rebar Placement, CPA, NSA and TCA only:

For CPA and TCA, same procedure as described above.

For NSA, all of the required water was placed in the mixer (rather than $3 / 4$ as described above) and the grout was mixed to a doughy state. This produced a slightly stiffer grout. The only other difference compared to vertical bars was the method of grout placement in the horizontal hole. A dessert decorator with plastic tubing fitted at the end was custom made so that the grout could flow smoothly into the hole by means of injection. Care was exercised to till up the hole as fully as possible prior to rebar placement.

Rebars were supported using a special bracing fitted around the concrete block. 
Table A.5: Test Results

\begin{tabular}{|c|c|c|c|c|c|c|c|}
\hline $\begin{array}{c}\text { Group } \\
\text { No. }\end{array}$ & $\begin{array}{l}\text { Specimen } \\
\text { labol" }\end{array}$ & $\begin{array}{l}\text { Anchorage } \\
\text { method"* }\end{array}$ & $\begin{array}{l}\text { Cover } \\
\text { in. }\end{array}$ & $\begin{array}{c}\text { Concrete } \\
\text { strength } \\
\text { psi }\end{array}$ & $\begin{array}{l}\text { Bond } \\
\text { strength } \\
\text { kips }\end{array}$ & $\begin{array}{l}\text { Mod. bond } \\
\text { strength } \\
\text { kips }\end{array}$ & $\begin{array}{l}\text { Failure } \\
\text { mode**. }\end{array}$ \\
\hline \multicolumn{8}{|c|}{ Groups 1 and 2} \\
\hline 1 & 5VC-M-6-7/8BW & NSANTR & 3 & 5310 & 17.95 & 17.42 & Pullout \\
\hline 2 & 5VC-M-6-7/8BW & NSA-NIR & $2-15 / 16$ & 5360 & 16.61 & 16.05 & $\mathbf{T}$ \\
\hline Avg & & & & & & 16.74 & \\
\hline 1 & $5 V C-M-6-13 / 16 B V$ & CPANTR & 3 & 5310 & 18.75 & 18.20 & $\mathbf{s}$ \\
\hline 2 & $5 V C-M-6-13 / 16 B V$ & CPANTR & $3-1 / 8$ & 5360 & 19.17 & 18.52 & $S / T$ \\
\hline Avg & & & & & & 18.36 & \\
\hline 1 & SVC-M-6-3/4BW & TCA-NTR & $2-15 / 16$ & 5310 & 14.38 & 13.96 & IGC \\
\hline 2 & 5VC-M-6-3/4BW & TCA-NTR & $3 \cdot 1 / 16$ & 5360 & & 15.43 & IGCrCone \\
\hline Avg & & & & & & 14.69 & \\
\hline 1 & 5VC-M-6-7/8BA & NSANTR & 3 & 5310 & 16.03 & 15.56 & $\mathbf{S}$ \\
\hline 2 & 5VC-M-6-7/8BA & NSANTR & $3-1 / 8$ & 5510 & 15.25 & 14.53 & Cone \\
\hline Avg & & & & & & 15.05 & \\
\hline 1 & $5 V C-M-6-13 / 16 B A$ & CPANIR & $2-15 / 16$ & 5390 & 14.85 & 14.30 & Pullout \\
\hline 2 & 5VC-M-6-13/16BA & CPANTR & $2-7 / 8$ & 5360 & 18.48 & 17.86 & $\mathbf{s}$ \\
\hline Avg & & & & & & 16.08 & \\
\hline 1 & $5 V C-M-6-3 / 4 B A$ & TCA-NTR & $2-3 / 4$ & 5310 & 8.16 & 7.92 & IGC \\
\hline 2 & $5 V C-M-6-3 / 4 B A$ & TCANTR & 3 & 5360 & 12.75 & 12.32 & IGC/Cone \\
\hline Avg & & & & & & 10.12 & \\
\hline 1 & $5 V C-M-6 \cdot 7 / 8 A$ & NSA-NTR & 3 & 5390 & 13.30 & 12.81 & IGC \\
\hline 2 & $5 V C-M-6-7 / 8 A$ & NSANTR & $3-1 / 16$ & 5510 & 17.91 & 17.07 & $\mathbf{S}$ \\
\hline Avg & & & & & & 14.94 & \\
\hline 1 & 5VC-M-6-13/16A & CPANIR & $3-1 / 8$ & 5310 & 18.56 & 18.02 & Pullout \\
\hline 2 & $5 V C \cdot M-6 \cdot 13 / 16 A$ & CPANTR & $2-15 / 16$ & 5360 & 17.00 & 16.43 & Pullout \\
\hline Avg & & & & & & 17.22 & \\
\hline 1 & $5 V C-M-6-3 / 4 A$ & TCA-NTR & $2-15 / 16$ & 5390 & 9.69 & 9.33 & IGC/Cone \\
\hline 2 & $5 V C-M-6-3 / 4 A$ & TCA-NIR & $2-7 / 8$ & 5360 & 10.93 & 10.56 & IGCICone \\
\hline Avg & & & & & & 9.95 & \\
\hline 1 & 5VC-M-6-1.5BW & NSANTR & $2 \cdot 3 / 4$ & 5310 & 15.65 & 15.19 & $\mathbf{s}$ \\
\hline 2 & 5VC-M-6-1.5BW & NSA-NTR & $2 \cdot 5 / 8$ & 5360 & 14.22 & 13.74 & $\mathrm{~s} / \mathrm{T}$ \\
\hline Avg & & & & & & 14.47 & \\
\hline 1 & 5VC-M-6-1.5BW & TCA-NTR & 3 & 5390 & 9.52 & 9.17 & IGC \\
\hline 2 & 5VC-M-6-1.5BW & TCA-NTR & $2-5 / 8$ & 5360 & 9.22 & 8.91 & IGC/S/Cone \\
\hline Avg & & & & & & 9.04 & \\
\hline 1 & 5VC-M-6-1.5BA & NSANTR & $2 \cdot 3 / 4$ & 5390 & 16.05 & 15.46 & IGC/S \\
\hline 2 & 5VC-M-6-1.5BA & NSANTR & 3 & 5360 & 19.10 & 18.46 & $\mathbf{T}$ \\
\hline Avg & & & & & & 16.96 & \\
\hline 1 & 5VC-M-6-1.5BA & TCA-NTR & 3 & 5310 & 11.25 & 10.92 & IGC \\
\hline 2 & $5 V C-M \cdot 6-1.58 A$ & TCA-NTR & $2-15 / 16$ & 5510 & 12.51 & 11.92 & IGC \\
\hline
\end{tabular}


Table A.5: Test Results, continued

\begin{tabular}{|c|c|c|c|c|c|c|c|}
\hline $\begin{array}{c}\text { Group } \\
\text { No. }\end{array}$ & $\begin{array}{l}\text { Specimen } \\
\text { label* }\end{array}$ & $\begin{array}{l}\text { Anchorage } \\
\text { method"* }\end{array}$ & $\begin{array}{l}\text { Cover } \\
\text { in. }\end{array}$ & $\begin{array}{c}\text { Concrete } \\
\text { strength } \\
\text { psi }\end{array}$ & $\begin{array}{l}\text { Bond } \\
\text { strength } \\
\text { kjps }\end{array}$ & $\begin{array}{l}\text { Mod. bond } \\
\text { strength } \cdots \\
\text { kips }\end{array}$ & $\begin{array}{c}\text { Failure } \\
\text { mode**. }\end{array}$ \\
\hline Avg & & & & & & 11.42 & \\
\hline 1 & $5 V C-M-6-1.5 A$ & NSANTR & $2 \cdot 13 / 16$ & 5310 & 15.80 & 15.34 & $\mathbf{T}$ \\
\hline 2 & $5 V C-M-6-1.5 A$ & NSANTR & $2 \cdot 11 / 16$ & 5360 & 15.24 & 14.73 & $S / T$ \\
\hline Avg & & & & & & 15.03 & \\
\hline 1 & $5 V C-M-6-1.5 A$ & TCANIR & $2 \cdot 7 / 8$ & 5360 & 13.71 & 13.25 & IGC \\
\hline 2 & 5VC-M-6-1.5A & TCA-NIR & $2-11 / 16$ & 5510 & 9.87 & 9.40 & IGC \\
\hline Avg & & & & & & 11.33 & \\
\hline 1 & 5VC-M-6 & CPANTR & 3 & 5310 & 15.31 & 14.86 & $T$ \\
\hline 2 & 5VC-M-6 & CPNTR & $3-1 / 16$ & 5510 & 14.56 & 13.87 & $S / T$ \\
\hline Avg & & & & & & 14.37 & \\
\hline 1 & SVC-E-6 & CPANTR & 3 & 5310 & 15.40 & 14.95 & $T$ \\
\hline 2 & 5VC-E-6 & CPATIR & $3-1 / 16$ & 5510 & 14.63 & 13.94 & $\mathbf{S} / \mathrm{T}$ \\
\hline Avg & & & & & & 14.44 & \\
\hline
\end{tabular}

Groups 4, 5 and 6

\begin{tabular}{|c|c|c|c|c|c|c|c|}
\hline 4 & 5VC-M-6-7/8BW & NSA & 3 & 5460 & 17.15 & 16.41 & $\mathbf{s}$ \\
\hline 5 & 5VC-M-6-7/8BW & NSA & $2-15 / 16$ & 5570 & 15.74 & 14.91 & $\mathbf{T}$ \\
\hline 6 & 5VC-M-6-7/8BW & NSA & $2 \cdot 15 / 16$ & 5410 & 14.46 & 13.90 & $\mathbf{s}$ \\
\hline Avg & & & & & & 15.08 & \\
\hline 5 & 5VC-E-6-7/8BW & NSA & 3 & 5570 & 16.14 & 15.29 & $\mathbf{s}$ \\
\hline 6 & 5VC-E.6-7/8BW & NSA & $2-3 / 4$ & 5410 & 11.36 & 10.92 & $\mathbf{s}$ \\
\hline Avg & & & & & & 13.11 & \\
\hline 4 & 5VC-E-6-7/8BW & NSB & $2-7 / 8$ & 5460 & 14.88 & 14.24 & S/Cone \\
\hline 5 & 5VC-E-6-7/8BW & NSB & $3-1 / 16$ & $\mathbf{5 5 7 0}$ & 15.26 & 14.46 & S/Cone \\
\hline 6 & SVC-E-6-7/8BW & NSB & 3 & 5410 & 14.38 & 13.82 & $\mathbf{S}$ \\
\hline Avg & & & & & & 14.17 & \\
\hline 4 & 5VC-E-6-7/8BW & $\mathrm{TCB}$ & $3-1 / 16$ & 5460 & 18.77 & 17.96 & $\mathbf{s}$ \\
\hline 5 & 5VC-E-6-7/8BW & TCB & $213 / 16$ & 5570 & 16.91 & 16.02 & $\mathbf{S}$ \\
\hline 6 & 5VC-E-6-7/8BW & TCB & $2 \cdot 7 / 8$ & 5410 & 14.00 & 13.46 & $\mathbf{s}$ \\
\hline Avg & & & & & & 15.81 & \\
\hline 4 & SVC-E-6-3/4BW & $\mathbf{C P B}$ & 3 & 5460 & 11.59 & 11.09 & S/Cone \\
\hline 5 & 5VC.E-6-3/4BW & CPB & $2-7 / 8$ & 5520 & 11.25 & 10.66 & S/Cone \\
\hline 6 & SVC-E-6-3/4BW & CPB & 3 & 5410 & 7.64 & 7.34 & IGCrCone \\
\hline Avg & & & & & & 9.70 & \\
\hline 4 & 5VC-E-6-13/16BU & CPA & 3 & 5460 & 13.44 & 12.86 & $\mathbf{s}$ \\
\hline 5 & 5VC-E-6-13/16BU & CPA & $2-13 / 16$ & 5570 & 10.51 & 9.96 & $\mathbf{s}$ \\
\hline 6 & SVC-E-6-13/16BU & CPA & $3-1 / 16$ & 5410 & 10.70 & 10.29 & $\mathbf{S}$ \\
\hline Avg & & & & & & 11.04 & \\
\hline 4 & 5VC-M-6-7/8BW & TCA & $3.1 / 16$ & 5460 & 11.20 & 10.72 & IGC/S \\
\hline 5 & 5VC-M-6-7/8BW & TCA & $2-15 / 16$ & 5570 & 13.35 & 12.65 & $\mathrm{~S} / \mathrm{T}$ \\
\hline
\end{tabular}


Table A.5: Test Results, continued

\begin{tabular}{|c|c|c|c|c|c|c|c|}
\hline $\begin{array}{c}\text { Group } \\
\text { No. }\end{array}$ & $\begin{array}{c}\text { Specimen } \\
\text { label* }\end{array}$ & $\begin{array}{l}\text { Anchorage } \\
\text { method"* }\end{array}$ & $\begin{array}{l}\text { Cover } \\
\text { in. }\end{array}$ & $\begin{array}{l}\text { Concrete } \\
\text { strength } \\
\text { psi }\end{array}$ & $\begin{array}{l}\text { Bond } \\
\text { strength } \\
\text { kips }\end{array}$ & $\begin{array}{l}\text { Mod. bond } \\
\text { strength".. } \\
\text { kips }\end{array}$ & $\begin{array}{c}\text { Failure } \\
\text { mode"*." }\end{array}$ \\
\hline 6 & 5VC-M-6-7/8BW & TCA & $2-15 / 16$ & 5410 & 7.61 & 7.32 & $T$ \\
\hline Avg & & & & & & 10.23 & \\
\hline 4 & 5VC-E-6-7/8BW & TCA & $2-15 / 16$ & 5460 & 13.49 & 12.91 & IGC/S/Cone \\
\hline 5 & 5VC-E-6-7/8BW & TCA & $2-7 / 8$ & 5570 & 12.79 & 12.12 & IGC/srCone \\
\hline 8 & 5VC-E-6-7/8BW & TCA & $2-7 / 8$ & 5410 & 10.59 & 10.18 & IGC/T/Cone \\
\hline Avg & & & & & & 11.74 & \\
\hline 4 & 5VC-M-6-1.5BW & NSA & $2-11 / 16$ & 5460 & 16.20 & 15.50 & $\mathbf{s}$ \\
\hline 5 & 5VC-M-6-1.5BW & NSA & $2-5 / 8$ & 5570 & 15.03 & 14.24 & s/T/Cone \\
\hline 6 & 5VC-M-6-1.5BW & NSA & $2-7 / 8$ & 5410 & 13.38 & 12.86 & $\mathbf{s}$ \\
\hline Avg & & & & & & 14.20 & \\
\hline 4 & 5VC-E-6-1.5BW & NSA & $3-1 / 16$ & 5460 & 16.74 & 16.02 & $\mathbf{s}$ \\
\hline 5 & 5VC-E-6-1.5BW & NSA & $2 \cdot 3 / 4$ & 5570 & 15.90 & 15.06 & $\mathbf{S}$ \\
\hline 6 & SVC-E-6-1.5BW & NSA & $3-1 / 16$ & 5410 & 14.28 & 13.73 & SiCono \\
\hline Avg & & & & & & 14.94 & \\
\hline 4 & 5VC-E-6-1.5BW & NSB & $2 \cdot 13 / 16$ & 5460 & 14.98 & 14.34 & Cone \\
\hline 5 & 5VC-E-6-1.5BW & NSB & $2-13 / 16$ & 5570 & 14.94 & 14.15 & $\mathbf{s}$ \\
\hline 6 & 5VC-E-6-1.5BW & $\mathbf{N S B}$ & $3-1 / 16$ & 5410 & 14.21 & 13.66 & $\mathbf{S}$ \\
\hline Avg & & & & & & 14.05 & \\
\hline 4 & 5VC-E-6-1.5BW & TCB & $2 \cdot 3 / 4$ & 5460 & 16.26 & 15.56 & $\mathbf{s}$ \\
\hline 5 & 5VC-E-6-1.5BW & TCB & $2-7 / 8$ & 5570 & 16.05 & 15.21 & $\mathbf{s}$ \\
\hline 6 & 5VC-E-6-1.5BW & TCB & $2-7 / 8$ & 5410 & 14.76 & 14.19 & $\mathbf{T}$ \\
\hline Avg & & & & & & 14.99 & \\
\hline 4 & 5VC-M-6-1.5BW & TCA & $2 \cdot 7 / 8$ & 5460 & 12.30 & 11.77 & IGCrCone \\
\hline 5 & 5VC-M-6-1.5BW & TCA & 3 & 5570 & 14.67 & 13.90 & recrs \\
\hline 6 & 5VC-M-6-1.5BW & TCA & $2 \cdot 15 / 16$ & 5410 & 12.08 & 11.61 & IGC/S/Cono \\
\hline Avg & & & & & & 12.43 & \\
\hline 4 & 5VC-E-6-1.5BW & TCA & $2 \cdot 5 / 8$ & 5460 & 12.65 & 12.11 & IGCrone \\
\hline 5 & 5VC-E-6-1.5BW & TCA & $2-11 / 16$ & 5570 & 14.52 & 13.76 & IGC/SICone \\
\hline 6 & 5VC-E-6-1.5BW & TCA & $2-13 / 16$ & 5410 & 12.27 & 11.80 & IGC/S/Cone \\
\hline Avg & & & & & & 12.52 & \\
\hline 4 & $5 V C-M-6-1.5 B A$ & NSA & 3 & 5460 & 17.79 & 17.02 & $\mathbf{s}$ \\
\hline 5 & 5VC-M-6-1.5BA & NSA & $2 \cdot 13 / 16$ & 5570 & 15.49 & 14.68 & $\mathbf{s}$ \\
\hline 6 & 5VC-M-6-1.5BA & NSA & $2-7 / 8$ & 5410 & 14.90 & 14.32 & $\mathbf{s}$ \\
\hline Avg & & & & & & 15.34 & \\
\hline 4 & $5 V C-M-6-1.5 A$ & NSA & $2-7 / 8$ & 5460 & 16.84 & 16.12 & $\mathbf{T}$ \\
\hline 5 & $5 V C-M-6-1.5 A$ & NSA & 3 & $\mathbf{5 5 7 0}$ & 16.52 & 15.65 & Iecrs \\
\hline 6 & 5VC-M-6-1.5A & NSA & $2-7 / 8$ & 5410 & 15.32 & 14.73 & $\mathbf{s}$ \\
\hline Avg & & & & & & 15.50 & \\
\hline 4 & SVC-M-6 & CIP & $3-1 / 16$ & 5460 & 16.82 & 16.10 & $\mathbf{s}$ \\
\hline 5 & 5VC-M-6 & CIP & 3 & 5570 & 17.50 & 16.58 & S/Cone \\
\hline
\end{tabular}


Table A.5: Test Results, continued

\begin{tabular}{|c|c|c|c|c|c|c|c|}
\hline $\begin{array}{c}\text { Group } \\
\text { No. }\end{array}$ & $\begin{array}{c}\text { Specimon } \\
\text { label" } \\
\end{array}$ & $\begin{array}{l}\text { Anchorage } \\
\text { method": }\end{array}$ & $\begin{array}{l}\text { Cover } \\
\text { in. }\end{array}$ & $\begin{array}{l}\text { Concrete } \\
\text { strength } \\
\text { psl }\end{array}$ & $\begin{array}{l}\text { Bond } \\
\text { strength } \\
\text { kips }\end{array}$ & $\begin{array}{l}\text { Mod. bond } \\
\text { strength } \\
\text { kips }\end{array}$ & $\begin{array}{c}\text { Failure } \\
\text { mode*** }\end{array}$ \\
\hline 6 & 5VC-M-6 & CIP & 3 & 5410 & 16.34 & 15.71 & $\mathbf{s}$ \\
\hline Avg & & & & & & 16.13 & \\
\hline 4 & 5VC-E-6 & CIP & 3 & 5460 & 17.73 & 16.97 & $\mathbf{s}$ \\
\hline 5 & 5VC-E-6 & CIP & 3 & 5570 & 17.16 & 16.26 & S/Cone \\
\hline 6 & 5VC-E-6 & CIP & 3 & 5410 & 15.57 & 14.97 & $\mathbf{s}$ \\
\hline \multirow[t]{2}{*}{ Avg } & & & & & & 16.06 & \\
\hline & . & \multicolumn{3}{|c|}{ Group 7} & & . & \\
\hline 7 & 5VC-E-6-7/8BW & TCB & $3-3 / 16$ & 4460 & 9.92 & 10.50 & IGC/Cone \\
\hline 7 & 5VC-E-6-7/8BW & TCB & $3-3 / 16$ & 4460 & 8.29 & 8.78 & IGC/Cono \\
\hline 7 & 5VC-E-6-7/8BW & TCB & $3-5 / 16$ & 4460 & 11.06 & 11.17 & IGC/Cone \\
\hline Avg & & & & & & 10.33 & \\
\hline 7 & 5VC-E-6-7/8BA & TCB & $3-1 / 16$ & 4460 & 8.36 & 8.85 & Cone \\
\hline 7 & 5VC-E-6-7/8BA & TCB & $3-1 / 8$ & 4460 & 13.18 & 13.96 & S/Cone \\
\hline 7 & 5VC-E-6-7/8BA & TCB & $3-1 / 4$ & 4460 & 11.61 & 12.29 & S/Cone \\
\hline Avg & & & & & & 11.70 & \\
\hline 7 & 5VC-E-6-7/8A & TCB & $3-1 / 4$ & 4460 & 13.70 & 14.51 & S/Cone \\
\hline 7 & 5VC-E-6-7/8A & TCB & $3-1 / 8$ & 4460 & 13.74 & 14.55 & $\mathbf{s}$ \\
\hline 7 & 5VC-E-6-7/8A & TCB & $3-1 / 4$ & 4460 & 14.65 & 15.51 & S/Cone \\
\hline Avg & & & & & & 14.86 & \\
\hline
\end{tabular}

Groups 8, 9 and 10

\begin{tabular}{|c|c|c|c|c|c|c|c|}
\hline 8 & 8VC-E-9-1.25V & NSA & 3 & 4710 & 24.62 & 25.37 & $\mathbf{s}$ \\
\hline 9 & $8 V C-E-9-1.25 V$ & NSA & $2 \cdot 7 / 8$ & 5360 & 24.96 & 24.11 & $\mathbf{s}$ \\
\hline 10 & 8VC-E-9-1.25V & NSA & 3 & 4970 & 24.89 & 24.97 & $\mathbf{s}$ \\
\hline Avg & & & & & & 24.81 & \\
\hline 8 & BVC-E-9-1.25BW & NSA & 3 & 4710 & 24.89 & 25.64 & $\mathbf{s}$ \\
\hline 9 & 8VC-E-9-1.25BW & NSA & 3 & 5360 & 22.86 & 22.08 & $\mathbf{S}$ \\
\hline 10 & BVC-E-9-1.25BW & NSA & $3 \cdot 1 / 4$ & 4970 & 27.79 & 27.87 & $\mathbf{s}$ \\
\hline Avg & & & & & & 25.20 & \\
\hline 8 & BVC-E-9-1.25BA & NSA & 3 & 4710 & 23.35 & 24.06 & $\mathbf{s}$ \\
\hline 9 & 8VC-E-9-1.25BA & NSA & $3-3 / 16$ & 5360 & 21.16 & 20.44 & $\mathbf{s}$ \\
\hline 10 & 8VC-E-9-1.25BA & NSA & $3-1 / 16$ & 4970 & 25.07 & 25.15 & $\mathbf{s}$ \\
\hline Avg & & & & & & 23.21 & \\
\hline 8 & $8 V C-E-9-1.25 A$ & NSA & 3 & 4710 & 21.66 & 22.32 & $\mathbf{s}$ \\
\hline 9 & $8 V C-E-9-1.25 \mathrm{~A}$ & NSA & $2-7 / 8$ & 5360 & 24.14 & 23.32 & $\mathbf{s}$ \\
\hline 10 & $8 V C-E-9-1.25 A$ & NSA & 3 & 4970 & 26.13 & 26.21 & $\mathbf{s}$ \\
\hline Avg & & & & & & 23.95 & \\
\hline
\end{tabular}


Table A.5: Test Results, continued

\begin{tabular}{|c|c|c|c|c|c|c|c|}
\hline $\begin{array}{c}\text { Group } \\
\text { No. }\end{array}$ & $\begin{array}{c}\text { Specimen } \\
\text { label* }\end{array}$ & $\begin{array}{l}\text { Anchorage } \\
\text { method }\end{array}$ & $\begin{array}{l}\text { Cover } \\
\text { in. }\end{array}$ & $\begin{array}{l}\text { Concrete } \\
\text { strength } \\
\text { psi }\end{array}$ & $\begin{array}{l}\text { Bond } \\
\text { strength } \\
\text { kips }\end{array}$ & $\begin{array}{l}\text { Mod. bond } \\
\text { strength } \\
\text { kips }\end{array}$ & $\begin{array}{l}\text { Failure } \\
\text { mode }\end{array}$ \\
\hline 8 & $8 V C-E-9-1.25 V$ & TCB & $3-3 / 16$ & 4710 & 24.24 & 24.98 & $\mathbf{s}$ \\
\hline 9 & $8 V C-E-9-1.25 \mathrm{~V}$ & $\mathrm{TCB}$ & $2-7 / 8$ & 5360 & 28.41 & 27.44 & $\mathbf{S}$ \\
\hline 10 & $8 V C-E-9-1.25 V$ & TCB & 3 & 4970 & 22.22 & 22.29 & $\mathbf{s}$ \\
\hline Avg & & & & & & 24.90 & \\
\hline 8 & BVC-E-9-1.25BW & TCB & 3 & 4710 & 21.53 & 22.18 & $\mathbf{s}$ \\
\hline 9 & BVC-E-9-1.25BW & TCB & $3-1 / 16$ & 5360 & 28.40 & 27.43 & $\mathbf{s}$ \\
\hline 10 & 8VC-E-9-1.25BW & TCB & $3-1 / 16$ & 4970 & 24.52 & 24.59 & $\mathbf{s}$ \\
\hline Avg & & & & & & 24.74 & \\
\hline 8 & 8VC-E-9-1.25BA & TCB & $3 \cdot 1 / 16$ & 4710 & 25.80 & 24.06 & $\mathbf{S}$ \\
\hline 9 & 8VC-E-9-1.25BA & TCB & 3 & 5360 & 25.76 & 20.44 & $\mathbf{s}$ \\
\hline 10 & 8VC-E-9-1.25BA & TCB & $2 \cdot 7 / 8$ & 4970 & 23.20 & 25.15 & $\mathbf{S}$ \\
\hline Avg & & & & & & 24.91 & \\
\hline 8 & 8VC-E-9-1.25A & TCB & $3-1 / 16$ & 4710 & 23.62 & 24.34 & $\mathbf{s}$ \\
\hline 9 & 8VC-E-9-1.25A & TCB & $3-1 / 8$ & $536 \dot{0}$ & 26.20 & 25.30 & $\mathbf{S}$ \\
\hline 10 & 8VC-E-9-1.25A & TCB & 3 & 4970 & 24.81 & 24.88 & $\mathbf{s}$ \\
\hline Avg & & & & $\cdot$ & & 24.84 & \\
\hline 8 & 8VC-E-9-1.25V & CPA & 3 & 4710 & 26.12 & 26.91 & $\mathbf{s}$ \\
\hline 9 & $8 V C-E-9-1.25 V$ & $C P A$ & $2-15 / 16$ & 5360 & 26.06 & 25.17 & $\mathbf{S}$ \\
\hline 10 & 8VC-E-9-1.25V & CPA & $3-1 / 8$ & 4970 & 24.97 & 25.05 & $\mathbf{s}$ \\
\hline Avg & & & & & & 25.71 & \\
\hline 8 & 8VC-E-9-1.25BW & CPA & 3 & 4710 & 27.30 & 28.13 & $\mathbf{s}$ \\
\hline 9 & 8VC-E-9-1.25BW & CPA & $2-7 / 8$ & 5360 & 25.15 & 24.29 & s \\
\hline 10 & BVC-E-9-1.25BW & CPA & $2-15 / 16$ & 4970 & 27.60 & 27.68 & $\mathbf{S}$ \\
\hline Avg & & & & & & 26.70 & \\
\hline 8 & 8VC-E-9-1.25BA & CPA & $3-1 / 8$ & 4710 & 27.81 & 28.65 & $\mathbf{S}$ \\
\hline 9 & 8VC-E-9-1.25BA & CPA & $3-1 / 16$ & 5360 & 27.63 & 26.69 & $\mathbf{s}$ \\
\hline 10 & 8VC-E-9-1.25BA & CPA & $2 \cdot 7 / 8$ & 4970 & 29.26 & 29.35 & $\mathbf{s}$ \\
\hline Avg & & & & & & 28.23 & \\
\hline 8 & 8VC-E-9-1.25A & CPA & $3 \cdot 1 / 16$ & 4710 & 27.25 & 28.08 & $\mathbf{s}$ \\
\hline 9 & 8VC-E-9-1.25A & $C P A$ & $3-1 / 8$ & 5360 & 28.46 & 27.49 & $\mathbf{s}$ \\
\hline 10 & 8VC-E-9-1.25A & CPA & 3 & 4970 & 26.84 & 26.92 & $\mathbf{S}$ \\
\hline Avg & & & & & & 27.49 & \\
\hline 8 & 8VC-E-9-1.25V & TCA & $2-7 / 8$ & 4710 & 23.86 & 24.58 & S/Cone \\
\hline 9 & 8VC-E-9-1.25V & TCA & $2-15 / 16$ & 5360 & 23.07 & 22.28 & $\mathbf{s}$ \\
\hline 10 & $8 V C-E-9-1.25 V$ & TCA & $2-15 / 16$ & 4970 & 23.34 & 23.41 & $\mathbf{s}$ \\
\hline Avg & & & & & & 23.43 & \\
\hline 8 & 8VC-E-9-1.25BW & TCA & 3 & 4710 & 15.47 & 15.94 & $\mathbf{s}$ \\
\hline 9 & 8VC-E-9-1.25BW & TCA & $3 \cdot 1 / 8$ & 5360 & 18.11 & 17.49 & $\mathbf{s}$ \\
\hline 10 & BVC-E-9-1.25BW & TCA & $3-1 / 16$ & 4970 & 16.41 & 16.46 & IGC/S \\
\hline Avg & & & & & & 16.63 & \\
\hline
\end{tabular}


Table A.5: Test Results, continued

\begin{tabular}{|c|c|c|c|c|c|c|c|}
\hline $\begin{array}{c}\text { Group } \\
\text { No. }\end{array}$ & $\begin{array}{c}\text { Specimen } \\
\text { label* }\end{array}$ & $\begin{array}{l}\text { Anchorage } \\
\text { method }\end{array}$ & $\begin{array}{l}\text { Cover } \\
\text { in. }\end{array}$ & $\begin{array}{c}\text { Concrete } \\
\text { strength } \\
\text { psi }\end{array}$ & $\begin{array}{l}\text { Bond } \\
\text { strength } \\
\text { kips }\end{array}$ & $\begin{array}{c}\text { Mod. bond } \\
\text { strength".. } \\
\text { kips }\end{array}$ & $\begin{array}{l}\text { Failure } \\
\text { mode }\end{array}$ \\
\hline 8 & 8VC-E-9-1.25BA & TCA & $2 \cdot 15 / 16$ & 4710 & 15.81 & 16.29 & S/Cone \\
\hline 9 & 8VC-E-9-1.25BA & TCA & $2 \cdot 7 / 8$ & 5360 & 11.55 & 11.16 & IGC/Cone \\
\hline 10 & 8VC-E-9-1.25BA & TCA & $3 \cdot 1 / 16$ & 4970 & 16.34 & 16.39 & IGCIS \\
\hline Avg & & & & & & 14.61 & \\
\hline 8 & 8VC-E-9-1.25A & TCA & 3 & 4710 & 19.86 & 20.46 & IGC/S \\
\hline 9 & 8VC-E-9-1.25A & TCA & 3 & 5360 & 16.57 & 16.00 & IGC/Cone \\
\hline 10 & $8 V C-E-9-1.25 A$ & TCA & 3 & 4970 & 13.77 & 13.81 & IGCT \\
\hline Avg & & & & & & 16.76 & \\
\hline 8 & $8 V C-M-9-1.25$ & CIP & $3-1 / 16$ & 4710 & 27.14 & 27.96 & $\mathbf{S}$ \\
\hline 9 & $8 V C-M-9-1.25$ & CIP & $3-1 / 16$ & 5360 & 27.45 & 26.51 & $\mathbf{s}$ \\
\hline 10 & 8VC-M-9-1.25 & CIP & $3 \cdot 1 / 16$ & 4970 & 28.78 & 28.87 & $\mathbf{S}$ \\
\hline Avg & & & & & & 27.78 & \\
\hline 8 & 8VC-E-9-1.25 & CIP & 3 & 4710 & 26.89 & 27.71 & $\mathbf{s}$ \\
\hline 9 & 8VC-E-9-1.25 & CIP & 3 & 5360 & 27.18 & 26.25 & $\mathbf{S}$ \\
\hline 10 & 8VC-E-9-1.25 & CIP & $3-1 / 16$ & 4970 & 24.02 & 24.09 & $\mathbf{s}$ \\
\hline \multirow[t]{2}{*}{ Avg } & 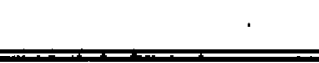 & & &. & & 26.02 & \\
\hline & & & Group 11 & & & & \\
\hline 11 & 5VC-E-6-13/16BA & CPA1CPS & $2-7 / 8$ & $\overline{5230}$ & 10.61 & 15.26 & $\overline{\mathbf{S}}$ \\
\hline 11 & 5VC-E-6-13/16BA & CPA-1CPS & $2 \cdot 15 / 16$ & 5230 & 13.60 & 13.30 & IGC/S \\
\hline 11 & 5VC-E-6-13/16BA & CPA1CPS & $3-1 / 16$ & 5230 & 11.35 & 11.10 & IGC \\
\hline Avg & & & & & & 13.22 & \\
\hline 11 & 5VC-E-6-13/16BA & CPA-2CPS & $2 \cdot 7 / 8$ & 5230 & 15.33 & 14.99 & $\mathbf{S}$ \\
\hline 11 & 5VC-E-6-13/16BA & CPA2CPS & 3 & 5230 & 14.08 & 13.77 & S/Cone \\
\hline 11 & 5VC-E-6-13/16BA & CPA2CPS & $3-1 / 8$ & 5230 & 14.23 & 13.91 & S/Cone \\
\hline Avg & & & & & & 14.22 & \\
\hline 11 & 5VC-E-6-13/16BA & CPA1CPE & $3 \cdot 1 / 16$ & 5230 & 17.20 & 16.82 & $\mathbf{S}$ \\
\hline 11 & 5VC-E-6-13/16BA & CPA-1CPE & $3-1 / 16$ & 5230 & 16.72 & 16.35 & $\mathbf{s}$ \\
\hline 11 & 5VC-E-6-13/16BA & CPA-1CPE & $2-15 / 16$ & 5230 & 13.33 & 13.03 & $\mathbf{S}$ \\
\hline Avg & & & & & & 15.40 & \\
\hline 11 & 5VC-E-6-13/16BA & CPA-2CPE & $2-7 / 8$ & 5230 & 14.83 & 14.50 & $\mathbf{S}$ \\
\hline 11 & 5VC-E-6-13/16BA & CPA-ZCPE & 3 & 5230 & 14.65 & 14.32 & $\mathbf{s}$ \\
\hline 11 & 5VC-E-6-13/16BA & CPAZCPE & $3 \cdot 1 / 8$ & 5230 & 14.44 & 14.12 & $\mathbf{S}$ \\
\hline Avg & & & & & & 14.31 & \\
\hline 11 & 5VC-E-6-7/8V & TCA & $2-15 / 16$ & 5230 & 9.86 & 9.64 & IGC \\
\hline 11 & 5VC-E-6-7/8V & TCA & 3 & 5230 & 12.28 & 12.01 & IGC/S/Cone \\
\hline 11 & 5VC-E-6-7/8V & TCA & $3-3 / 16$ & 5230 & 11.86 & 11.60 & IGC/S \\
\hline Avg & & & & & & 11.08 & \\
\hline 11 & 5VC-E-6-7/8BA & TCA & $3-1 / 16$ & 5230 & 6.86 & 6.71 & IGC \\
\hline 11 & 5VC-E-6-7/8BA & TCA & 3 & 5230 & 13.09 & 12.80 & IGC/S/Cone \\
\hline
\end{tabular}


Table A.5: Test Results, continued

\begin{tabular}{|c|c|c|c|c|c|c|c|}
\hline $\begin{array}{c}\text { Group } \\
\text { No. }\end{array}$ & $\begin{array}{c}\text { Specimen } \\
\text { label* }\end{array}$ & $\begin{array}{l}\text { Anchorage } \\
\text { method": }\end{array}$ & $\begin{array}{l}\text { Cover } \\
\text { in. }\end{array}$ & $\begin{array}{l}\text { Conçrete } \\
\text { strength } \\
\text { psi }\end{array}$ & $\begin{array}{l}\text { Bond } \\
\text { strength } \\
\text { kips }\end{array}$ & $\begin{array}{c}\text { Mod. bond } \\
\text { strength"... } \\
\text { kips }\end{array}$ & $\begin{array}{c}\text { Failure } \\
\text { mode"*. }\end{array}$ \\
\hline $\begin{array}{l}11 \\
\text { Avg } \\
\end{array}$ & 5VC-E-6-7/8BA & TCA & $3-1 / 8$ & 5230 & 10.73 & $\begin{array}{l}10.49 \\
10.00 \\
\end{array}$ & IGCIS \\
\hline \multicolumn{8}{|c|}{ Groups 12,13 and 14} \\
\hline 12 & BVC-E-6-1.25BA & TCB & $2 \cdot 7 / 8$ & 5270 & 17.69 & 17.23 & $\mathbf{S}$ \\
\hline 13 & BVC-E-6-1.25BA & TCB. & $2-15 / 16$ & 5600 & 16.97 & 16.04 & $\mathbf{s}$ \\
\hline 14 & 8VC-E-6-1.25BA & TCB & $3 \cdot 1 / 8$ & 4550 & 18.33 & 19.22 & $\mathbf{S}$ \\
\hline Avg & & & & & & 17.50 & \\
\hline 12 & BVC-E-9-1.25BA & TCB & $3-1 / 8$ & 5270 & 24.59 & 23.95 & $\mathbf{S}$ \\
\hline 13 & BVC-E-9-1.25BA & TCB & $2-15 / 16$ & 5600 & 23.69 & 22.38 & $\mathbf{s}$ \\
\hline 14 & 8VC-E-9-1.25BA & TCB & $2-3 / 4$ & 4550 & 22.76 & 23.86 & $\mathbf{s}$ \\
\hline Avg & & & & & & 23.40 & \\
\hline 12 & 8VC-E-12-1.25BA & TCB & 3 & 5270 & 28.59 & 27.85 & $\mathbf{s}$ \\
\hline 13 & 8VC-E-12-1.25BA & TCB & $2 \cdot 7 / 8$ & 5600 & 31.56 & 29.82 & $\mathbf{S}$ \\
\hline 14 & 8VC-E-12-1.25BA & TCB & 3 & 4550 & 33.34 & 34.95 & $\mathbf{S}$ \\
\hline Avg & & & & - & & 30.87 & \\
\hline 12 & 8VC-E-15-1.25BA & TCB & $2-13 / 16$ & 5270 & 34.78 & 33.88 & $\mathbf{s}$ \\
\hline 13 & $8 V C-E-15-1.25 B A$ & TCB & $3-1 / 16$ & 5600 & 42.03 & 39.71 & $\mathbf{S}$ \\
\hline 14 & 8VC-E-15-1.25BA & TCB & $3 \cdot 1 / 8$ & 4550 & 40.63 & 42.59 & $\mathbf{S}$ \\
\hline Avg & & & & . & & 38.73 & \\
\hline 12 & 8VC-E-6-1.25BA & TCA & $2-7 / 8$ & 5270 & 13.57 & 13.22 & kCAs \\
\hline 13 & 8VC-E-6-1.25BA & TCA & $3-1 / 4$ & 5600 & 14.16 & 13.38 & IGC/S \\
\hline 14 & 8VC-E-6-1.25BA & TCA & 3 & 4550 & 11.69 & 12.25 & IGC/Cone \\
\hline Avg & & & & & & 12.95 & \\
\hline 12 & 8VC-E-9-1.25BA & TCA & $2-3 / 4$ & 5270 & 17.98 & 17.51 & $\mathbf{S}$ \\
\hline 13 & 8VC-E-9-1.25BA & TCA & 3 & 5600 & 13.53 & 12.78 & IGC/T/S \\
\hline 14 & BVC-E-9-1.25BA & TCA & 3 & 4550 & 20.71 & 21.71 & IGC/T/Cone \\
\hline Avg & & & & & & 17.33 & \\
\hline 12 & 8VC-E-12-1.25BA & TCA & $3 \cdot 1 / 8$ & 5270 & 24.07 & 23.45 & IGC/S/T \\
\hline 13 & BVC-E-12-1.25BA & TCA & 3 & 5600 & 25.75 & 24.33 & IGC/Cone \\
\hline Avg & & & & & & 23.89 & \\
\hline 12 & 8VC-E-13-1.25BA & TCA & $3 \cdot 1 / 16$ & 5270 & 28.23 & 27.50 & IGC/S/T \\
\hline 13 & BVC-E-15-1.25BA & TCA & 3 & 5600 & 31.41 & 29.68 & IGC/S/Cone \\
\hline 14 & BVC-E-15-1.25BA & TCA & 3 & 4550 & 32.96 & 34.55 & IGC/S/Cone \\
\hline Avg & & & & & & 32.11 & \\
\hline 12 & $8 V C \cdot M-6-1.25$ & CIP & $3-1 / 16$ & 5270 & 18.09 & 17.62 & $\mathbf{s}$ \\
\hline 13 & 8VC-M-6-1.25 & CIP & 3 & 5600 & 18.57 & 17.55 & $\mathbf{S}$ \\
\hline 14 & 8VC-M-6-1.25 & CIP & $3-1 / 8$ & 4550 & 17.33 & 18.17 & $\mathbf{s}$ \\
\hline Avg & & & & & & 17.78 & \\
\hline
\end{tabular}


Table A.5: Test Results, continued

\begin{tabular}{|c|c|c|c|c|c|c|c|}
\hline $\begin{array}{c}\text { Group } \\
\text { No. }\end{array}$ & $\begin{array}{l}\text { Specimen } \\
\text { label" }\end{array}$ & $\begin{array}{l}\text { Anchorage } \\
\text { method"* }\end{array}$ & $\begin{array}{l}\text { Cover } \\
\text { in. }\end{array}$ & $\begin{array}{l}\text { Concrete } \\
\text { strength } \\
\text { poi }\end{array}$ & $\begin{array}{l}\text { Bond } \\
\text { strength } \\
\text { kips }\end{array}$ & $\begin{array}{l}\text { Mod. bond } \\
\text { strength } \\
\text { kips }\end{array}$ & $\begin{array}{c}\text { Failure } \\
\text { mode*e* }\end{array}$ \\
\hline 12 & $8 V C-M-9-1.25$ & CIP & $3.1 / 16$ & 5270 & 29.50 & 28.73 & $\mathbf{s}$ \\
\hline 13 & $8 V C \cdot M \cdot 9-1.25$ & CIP & 3 & 5600 & 28.97 & 27.37 & $\mathbf{s}$ \\
\hline 14 & $8 V C-M-9-1.25$ & CIP & $3-1 / 16$ & 4550 & 28.17 & 29.53 & $\mathbf{S}$ \\
\hline Avg & & & & & & 28.54 & \\
\hline 12 & $8 V C: M-12-1.25$ & CIP & 3 & 5270 & 38.20 & 37.21 & $\mathbf{s}$ \\
\hline 13 & $8 V C \cdot M \cdot 12 \cdot 1.25$ & CIP & 3 & 5600 & 35.67 & 33.70 & $\mathbf{s}$ \\
\hline 14 & 8VC-M-12-1.25 & CIP & $3 \cdot 1 / 16$ & 4550 & 36.86 & 38.64 & $\mathbf{s}$ \\
\hline Avg & & & & & & 36.52 & \\
\hline 12 & 8VC-M-15-1.25 & CIP & $3-1 / 16$ & 5270 & 45.04 & 43.87 & $\mathbf{s}$ \\
\hline 13 & 8VC-M-15-1.25 & CIP & $3 \cdot 1 / 16$ & 5600 & 47.67 & 45.04 & $\mathbf{s}$ \\
\hline 14 & $8 V C-M-15-1.25$ & CIP & 3 & 4550 & 44.96 & 47.13 & $\mathbf{S}$ \\
\hline Avg & & & & & & 45.35 & \\
\hline 12 & BVC-E-6-1.25 & CIP & $3-1 / 8$ & 5270 & 16.53 & 16.10 & $\mathbf{S}$ \\
\hline 13 & 8VC-E-6-1.25 & CIP & 3 & 5600 & 15.67 & 14.81 & $\mathbf{s}$ \\
\hline 14 & 8VC-E-6-1.25 & CIP & $3-1 / 16$ & 4550 & 16.42 & 17.21 & $\mathbf{s}$ \\
\hline Avg & & & & , & & 16.04 & \\
\hline 12 & 8VC-E-9-1.25 & CIP & 3 & 5270 & 25.20 & 24.55 & $\mathbf{s}$ \\
\hline 13 & 8VC-E-9-1.25 & CIP & 3 & 5600 & 24.45 & 23.10 & $\mathbf{s}$ \\
\hline 14 & 8VC-E-9-1.25 & CIP & 3 & 4550 & 24.31 & 25.48 & $\mathbf{S}$ \\
\hline Avg & & & & & & 24.38 & \\
\hline 12 & 8VC-E-12-1.25 & CIP & $3 \cdot 1 / 16$ & 5270 & 34.47 & 33.58 & $\mathbf{s}$ \\
\hline 13 & $8 V C-E-12-1.25$ & CIP & 3 & 5600 & 30.18 & 28.52 & $\mathbf{s}$ \\
\hline 14 & $8 V C-E \cdot 12-1.25$ & CIP & $3-1 / 8$ & 4550 & 30.04 & 31.49 & $\mathbf{s}$ \\
\hline Avg & & & & & & 31.20 & \\
\hline 12 & 8VC-E-15-1.25 & CIP & 3 & 5270 & 43.58 & 42.45 & $\mathbf{S}$ \\
\hline 13 & 8VC-E-15-1.25 & CIP & 3 & 5600 & 39.11 & 36.96 & $\mathbf{S}$ \\
\hline 14 & $8 V C \cdot E \cdot 15-1.25$ & CIP & $3-1 / 16$ & 4550 & 35.98 & 37.72 & $\mathbf{S}$ \\
\hline Avg & & & & & & 39.04 & \\
\hline
\end{tabular}

Groups 15, 16 and 17

\begin{tabular}{llllcccc}
\hline \hline 15 & 5VC-E-4-7/8BA & TCB & 3 & 5480 & 10.11 & 9.66 & $\mathrm{~S}$ \\
16 & 5VC-E-4-7/8BA & TCB & $2-15 / 16$ & 4610 & 9.72 & 10.12 & $\mathrm{~S}$ \\
17 & 5VC-E-4-7/8BA & TCB & $3-1 / 16$ & 4980 & 9.34 & 9.36 & $\mathrm{~S}$ \\
Avg & & & & & & 9.71 & \\
15 & 5VC-E-6-7/8BA & TCB & $2-7 / 8$ & 5360 & 15.00 & 14.49 & S/Cone \\
16 & 5VC-E-6-7/8BA & TCB & $2-7 / 8$ & 4610 & 15.06 & $15: 68$ & S \\
17 & 5VC-E-6-7/8BA & TCB & $2-7 / 8$ & 4980 & 14.24 & 14.27 & S/Cone \\
Avg & & & & & & 14.81 & \\
15 & 5VC-E-9-7/8BA & TCB & $2-7 / 8$ & 5360 & 18.36 & 17.73 & S/Cone \\
16 & 5VC-E-9-7/8BA & TCB & $3-1 / 16$ & 4610 & 22.86 & 23.81 & S/Cone
\end{tabular}


Table A.5: Test Results, continued

\begin{tabular}{|c|c|c|c|c|c|c|c|}
\hline $\begin{array}{c}\text { Group } \\
\text { No. }\end{array}$ & $\begin{array}{l}\text { Specimen } \\
\text { label" }\end{array}$ & $\begin{array}{l}\text { Anchorage } \\
\text { mothod"• }\end{array}$ & $\begin{array}{l}\text { Cover } \\
\text { in. }\end{array}$ & $\begin{array}{l}\text { Concrete } \\
\text { strength } \\
\text { psi }\end{array}$ & $\begin{array}{l}\text { Bond } \\
\text { strength } \\
\text { kips }\end{array}$ & $\begin{array}{l}\text { Mod. bond } \\
\text { strength } \\
\text { kips }\end{array}$ & $\begin{array}{c}\text { Failure } \\
\text { mode**. }\end{array}$ \\
\hline 17 & 5VC.E-9-7/8BA & TCB & $2-7 / 8$ & 4980 & 21.06 & 21.10 & SICone \\
\hline Avg & & & & & & 20.88 & \\
\hline 15 & 5VC-E-12-7/8BA & TCB & $2 \cdot 13 / 16$ & 5360 & 26.92 & 26.00 & Cone \\
\hline 16 & 5VC-E-12-7/8BA & TCB & $2-7 / 8$ & 4610 & 28.23 & 29.40 & IGC/S/Cone \\
\hline 17 & 5VC-E-12-7/8BA & TCB & $2-3 / 4$ & 4980 & 25.92 & 25.97 & SICone \\
\hline Avg & & & & & & 27.12 & \\
\hline 15 & 5VS-E-4-7/8BA & TCB $\cdots$ & $s+\cdots \cdot \cdot$ & 5480 & 9.13 & 8.72 & $\mathbf{s}$ \\
\hline 16 & 5VS-E-4-7/8BA & TCB & $2-13 / 16$ & 4610 & 8.81 & 9.18 & S/Cone \\
\hline 17 & 5VS-E-4-7/8BA & TCB & $2 \cdot 7 / 8$ & 4980 & 8.91 & 8.93 & S/Cone \\
\hline Avg & & & & & & 8.94 & \\
\hline 15 & 5VS-E-6-7/8BA & TCB & $2 \cdot 3 / 4$ & 5870 & 15.32 & 14.14 & $\mathbf{s}$ \\
\hline 16 & SVS-E-6-7/8BA & TCB & $3-1 / 8$ & 4610 & 11.94 & 12.43 & S/Cone \\
\hline 17 & 5VS-E-6-7/8BA & TCB & $3-1 / 16$ & 4980 & 13.75 & 13.78 & S/Cone \\
\hline Avg & & & & & & 13.45 & \\
\hline 15 & 5VS-E-9-7/8BA & TCB & $2-3 / 4$ & 5870 & 21.10 & 19.47 & S/Cone \\
\hline 16 & 5VS-E-9-7/8BA & TCB & 3 & 4610 & 21.34 & 22.22 & SICone \\
\hline 17 & 5VS-E-9-7/8BA & TCB & $.2-15 / 16$ & 4980 & 21.24 & 21.28 & S/Cone \\
\hline Avg & & & & & & 20.99 & \\
\hline 15 & 5VS-E-12-7/8BA & TCB & $2-7 / 8$ & 5480 & 29.51 & 28.19 & S/Cone \\
\hline 16 & 5VS-E-12-7/8BA & TCB & $2-13 / 16$ & 4610 & 25.17 & 26.21 & SiCone \\
\hline 17 & 5VS-E-12-7/8BA & TCB & $3-1 / 16$ & 4980 & 22.76 & 22.81 & S/Cone \\
\hline Avg & & & & & & 25.74 & \\
\hline 15 & 5VC-E-4-7/8BA & TCA & $2-15 / 16$ & 58970 & 7.74 & 7.14 & Cone \\
\hline 16 & 5VC-E-4-7/8BA & TCA & $2-7 / 8$ & 4610 & 7.34 & 7.64 & Cone \\
\hline 17 & 5VC-E-4-7/8BA & TCA & $3-1 / 16$ & 4980 & 6.82 & 6.83 & IGCreone \\
\hline Avg & & & & & & 7.21 & \\
\hline 15 & 5VC-E-6-7/8BA & TCA & 3 & 5870 & 11.69 & 10.79 & IGCrCone \\
\hline 16 & 5VC-E-6-7/8BA & TCA & $2 \cdot 15 / 16$ & 4610 & 11.79 & 12.28 & IGCreone \\
\hline 17 & 5VC-E-6-7/8BA & TCA & $2-7 / 8$ & 4980 & 8.11 & 8.13 & IGCrCone \\
\hline Avg & & & & & & 10.40 & \\
\hline 15 & 5VC-E-9-7/8BA & TCA & $2 \cdot 3 / 4$ & 5870 & 14.20 & 13.11 & Cone \\
\hline 16 & 5VC-E-9-7/8BA & TCA & $2-1 / 2$ & 4610 & 16.02 & 16.68 & IGCrCone \\
\hline 17 & 5VC-E-9-7/8BA & TCA & $2-7 / 8$ & 4980 & 15.67 & 15.70 & IGCiCone \\
\hline Avg & & & & & & 15.16 & \\
\hline 15 & 5VC-E-12-7/8BA & TCA & $2-15 / 16$ & 5870 & 19.80 & 18.27 & IGC/Cone \\
\hline 16 & 5VC-E-12-7/8BA & TCA & $3-1 / 16$ & 4610 & 23.17 & 24.13 & S/Cone \\
\hline 17 & 5VC-E-12-7/8BA & TCA & 3 & 4980 & 24.15 & 24.20 & IGCrene \\
\hline Avg & & & & & & 22.20 & \\
\hline 15 & $5 V C-M-4$ & CIP & $3 \cdot 1 / 4$ & 5360 & 10.12 & 9.77 & S/Cone \\
\hline 16 & $5 V C-M-4$ & CIP & 3 & 4610 & 9.37 & 9.76 & $\mathbf{s}$ \\
\hline
\end{tabular}


Table A.5: Test Results, continued

\begin{tabular}{|c|c|c|c|c|c|c|c|}
\hline $\begin{array}{c}\text { Group } \\
\text { No. }\end{array}$ & $\begin{array}{l}\text { Specimen } \\
\text { label" }\end{array}$ & $\begin{array}{l}\text { Anchorage } \\
\text { method"• }\end{array}$ & $\begin{array}{l}\text { Cover } \\
\text { in. }\end{array}$ & $\begin{array}{c}\text { Concrete } \\
\text { strongth } \\
\text { psi }\end{array}$ & $\begin{array}{l}\text { Bond } \\
\text { strength } \\
\text { klps }\end{array}$ & $\begin{array}{l}\text { Mod. bond } \\
\text { strength ... } \\
\text { kips }\end{array}$ & $\begin{array}{c}\text { Fallure } \\
\text { mode*... }\end{array}$ \\
\hline 17 & 5VC-M-4 & $\overline{C I P}$ & $3 \cdot 1 / 16$ & 4980 & 10.21 & 10.23 & $\mathbf{s}$ \\
\hline Avg & & & & & & 9.92 & \\
\hline 15 & 5VC-M-6 & CIP & 3 & 5360 & 15.68 & 15.14 & S/Cone \\
\hline 16 & 5VC-M-6 & CIP & 3 & 4610 & 15.35 & 15.99 & $\mathbf{s}$ \\
\hline 17 & 5VC-M-6 & CIP & $3-1 / 16$ & 4980 & 16.38 & 16.41 & $\mathbf{s}$ \\
\hline Avg & & & & & & 15.85 & \\
\hline 15 & 5VC-M-9 & CIP & 3 & 5360 & 22.14 & 21.38 & Pullout \\
\hline 16 & 5VC-M-9 & CIP & 3 & 4610 & 25.11 & 26.15 & Cone \\
\hline 17. & SVC-M-9 & CIP & 3 & 4980 & 22.74 & 22.79 & $\mathbf{s}$ \\
\hline Avg & & & & & & 23.44 & \\
\hline 15 & $5 V C-M-12$ & CIP & 3 & 5360 & 26.99 & 26.07 & Cone \\
\hline 16 & 5VC-M-12 & CIP & 3 & 4610 & 24.62 & 25.64 & Cone \\
\hline 17 & 5VC-M-12 & CIP & 3 & 4980 & 28.09 & 28.15 & S/Cone \\
\hline Avg & & & & & & 26.62 & \\
\hline 15 & 5VC-E-4 & CIP & 3 & 5480 & 9.29 & 8.87 & $\mathbf{s}$ \\
\hline 16 & 5VC-E-4 & CIP & 3 & 4610 & 10.41 & 10.84 & $\mathbf{s}$ \\
\hline 17 & 5VC-E-4 & CIP & 3 & 4980 & 9.42 & 9.44 & $\mathbf{s}$ \\
\hline Avg & & & & & & 9.72 & \\
\hline 15 & 5VC-E-6 & CIP & $3-1 / 16$ & 5480 & 15.82 & 15.11 & $\mathbf{s}$ \\
\hline 16 & 5VC-E-6 & CIP & $3-1 / 16$ & 4610 & 14.20 & 14.79 & $\mathbf{s}$ \\
\hline 17 & 5VC-E-6 & CIP & $2-15 / 16$ & 4980 & 15.30 & 15.33 & $\mathbf{s}$ \\
\hline Avg & & & & & & 15.08 & \\
\hline 15 & 5VC-E.9 & CIP & $3-1 / 16$ & 5480 & 23.18 & 22.14 & $s$ \\
\hline 16 & 5VC-E-9 & CIP & $3.1 / 16$ & 4610 & 21.09 & 21.96 & $\mathbf{s}$ \\
\hline 17 & 5VC-E-9 & CIP & 3 & 4980 & 23.03 & 23.08 & $\mathbf{s}$ \\
\hline Avg & & & & & & 22.40 & \\
\hline 15 & SVC-E-12 & CIP & 3 & 5480 & 28.88 & 27.59 & S/Cone \\
\hline 16 & 5VC-E-12 & CIP & $3 \cdot 1 / 16$ & 4610 & 30.26 & 31.51 & S/Cone \\
\hline 17 & SVC-E-12 & CIP & 3 & 4980 & 29.78 & 29.84 & Cone \\
\hline Avg & & & & & & 29.65 & \\
\hline 15 & 5VS-E-4 & CIP & 3 & 5870 & 8.72 & 8.05 & S/Cone \\
\hline 16 & 5VS-E-4 & CIP & 3 & 4610 & 9.04 & 9.41 & $\mathbf{s}$ \\
\hline 17 & 5VS-E-4 & CIP & 3 & 4980 & 8.74 & 8.76 & $\mathbf{s}$ \\
\hline Avg & & & & & & 8.74 & \\
\hline 15 & 5VS-E-6 & CIP & $3 \cdot 1 / 8$ & 5870 & 14.73 & 13.59 & $\mathbf{s}$ \\
\hline 16 & 5VS-E-6 & CIP & 3 & 4610 & 13.23 & 13.78 & $\mathbf{s}$ \\
\hline 17 & 5VS-E-6 & CIP & $3-1 / 16$ & 4980 & 14.57 & 14.60 & s \\
\hline Avg & & & & & & 13.99 & \\
\hline 15 & 5VS-E-9 & CIP & $3-1 / 8$ & 5870 & 23.38 & 21.58 & $\mathbf{s}$ \\
\hline 16 & 5VS-E-9 & CIP & 3 & 4610 & 19.46 & 20.27 & $\mathbf{s}$ \\
\hline
\end{tabular}


Table A.5: Test Results, continued

\begin{tabular}{|c|c|c|c|c|c|c|c|}
\hline $\begin{array}{c}\text { Group } \\
\text { No. }\end{array}$ & $\begin{array}{c}\text { Specimen } \\
\text { label* }\end{array}$ & $\begin{array}{l}\text { Anchorage } \\
\text { method"* }\end{array}$ & $\begin{array}{l}\text { Cover } \\
\text { in. }\end{array}$ & $\begin{array}{c}\text { Concrete } \\
\text { strength } \\
\text { psi }\end{array}$ & $\begin{array}{l}\text { Bond } \\
\text { strength } \\
\text { kips }\end{array}$ & $\begin{array}{l}\text { Mod. bond } \\
\text { strength } \cdots \\
\text { kips }\end{array}$ & $\begin{array}{c}\text { Failure } \\
\text { mode }\end{array}$ \\
\hline 17 & 5VS-E-9 & CIP & 3 & 4980 & 21.55 & 21.59 & S/Cone \\
\hline Avg & & & & & & 21.15 & \\
\hline 15 & 5VS-E-12 & CIP & 3. & 5870 & 25.50 & 23.53 & Pullout \\
\hline 16 & SVS-E-12 & CIP & $3-1 / 16$ & 4610 & 27.59 & 28.73 & $\mathbf{s}$ \\
\hline 17 & 5VS-E-12 & CIP & $3-1 / 16$ & 4980 & 26.61 & 26.66 & S/Cone \\
\hline \multirow[t]{2}{*}{ Avg } & & & & & & 26.31 & \\
\hline & & & Groups 18 & and 20 & & & \\
\hline 18 & 8HC-T-E-6-1.25BA & NSA & $2-15 / 16$ & 5400 & 12.96 & 12.47 & $T$ \\
\hline 18 & BHC-T-E-9-1.25BA & NSA & $3-1 / 16$ & 5400 & 18.68 & 17.97 & $\mathbf{s}$ \\
\hline 18 & BHC-T-E-12-1.25B & NSA & 3 & 5400 & 29.78 & 28.66 & $\mathbf{s}$ \\
\hline 18 & 8HC-T-E-6-1.25BA & CPA & 3 & 5400 & 19.60 & 18.86 & $\mathbf{s}$ \\
\hline 20 & BHC-T-E-6-1.25BA & CPA & $2-15 / 16$ & 5230 & 15.53 & 15.18 & $\mathbf{s}$ \\
\hline Avg & & & & & & 17.02 & \\
\hline 18 & 8HC-T-E-9-1.25BA & CPA & $3-1 / 16$ & 5400 & 28.23 & 27.16 & $\mathbf{S}$ \\
\hline 20 & 8HC-T-E-9-1.25BA & CPA & 3 & 5230 & 29.25 & 28.6 & $\mathbf{s}$ \\
\hline Avg & & & & & & 27.88 & \\
\hline 18 & 8HC-T-E-12-1.25B & CPA & $2 \cdot 15 / 16$ & 5400 & 35.64 & 34.29 & $\mathbf{s}$ \\
\hline 20 & $8 H C-T-E-12-1.25 B$ & CPA & $2 \cdot 13 / 16$ & 5230 & 31.09 & 30.4 & $\mathbf{s}$ \\
\hline Avg & 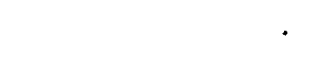 & & & & & 32.35 & \\
\hline 20 & $8 H C-T-E-15-1.25 B$ & CPA & $2 \cdot 7 / 8$ & 5230 & 35 & 34.22 & Pullout \\
\hline 20 & $8 H C-T-E-15-1.25 B$ & CPA & $3-1 / 16$ & 5230 & 46.75 & 45.71 & $\mathbf{s}$ \\
\hline Avg & & & & & & 39.97 & \\
\hline 18 & 8HC-T-E-6-1.25BA & TCA & $2-15 / 16$ & 5400 & 17.64 & 16.97 & KCAS \\
\hline 20 & 8HC-T-E-6-1.25BA & TCA & 3 & 5230 & 11.61 & 11.35 & IGCT \\
\hline Avg & & & & & & 14.16 & \\
\hline 18 & $8 H C-T-E-9-1.25 B A$ & TCA & $2 \cdot 3 / 4$ & 5400 & 17.02 & 16.38 & $\mathbf{S}$ \\
\hline 20 & 8HC-T-E-9-1.25BA & TCA & $3-1 / 16$ & 5230 & 18.43 & 18.02 & IGC $\pi$ \\
\hline Avg & & & & & & 17.2 & \\
\hline 18 & BHC-T-E-12-1.25B & TCA & $2-15 / 16$ & 5400 & 30.42 & 29.27 & S/Cone \\
\hline 20 & 8HC-T-E-15-1.25B & TCA & $2-15 / 16$ & 5230 & 31.15 & 30.46 & IGas \\
\hline 20 & 8HC-T-E-15-1.25B & TCA & $3-1 / 8$ & 5230 & 31.52 & 30.87 & IGCN \\
\hline Avg & & & & & & 30.67 & \\
\hline 18 & BHC-T-E-9 & CIP & 3 & 5400 & 25.58 & 24.61 & $\mathbf{s}$ \\
\hline 18 & 8HC-T-E-9 & CIP & $3-1 / 8$ & 5400 & 27.38 & 26.35 & $\mathbf{S}$ \\
\hline 18 & 8HC-T-E-9 & CIP & $3-3 / 16$ & 5400 & 27.89 & 26.84 & $\mathbf{s}$ \\
\hline Avg & & & & & & 25.93 & \\
\hline 20 & $8 H C-T-E-12$ & CIP & $3 \cdot 1 / 16$ & 5230 & 29.87 & 29.21 & $\mathbf{S}$ \\
\hline 20 & 8HC-T-E-15 & CIP & $3-1 / 4$ & 5230 & 41.55 & 40.63 & $\mathbf{s}$ \\
\hline
\end{tabular}


Table A.5: Test Results, continued

\begin{tabular}{|c|c|c|c|c|c|c|c|}
\hline $\begin{array}{l}\text { Group } \\
\text { No. }\end{array}$ & $\begin{array}{c}\text { Specimen } \\
\text { |abel| }\end{array}$ & $\begin{array}{l}\text { Anchorage } \\
\text { method"* }\end{array}$ & $\begin{array}{l}\text { Cover } \\
\text { in. }\end{array}$ & $\begin{array}{c}\text { Concrete } \\
\text { strength } \\
\text { psi }\end{array}$ & $\begin{array}{l}\text { Bond } \\
\text { strength } \\
\text { kips }\end{array}$ & $\begin{array}{l}\text { Mod. bond } \\
\text { strength... } \\
\text { kips }\end{array}$ & $\begin{array}{l}\text { Failure } \\
\text { mode*... }\end{array}$ \\
\hline
\end{tabular}

\begin{tabular}{|c|c|c|c|c|c|c|c|}
\hline 18 & 8HC-B-E-6-1.25BA & NSA & $2.7 / 8$ & 5400 & 11.01 & 10.59 & $\mathbf{T}$ \\
\hline 18 & $8 H C-B-E-9-1.25 B A$ & NSA & $3 \cdot 1 / 4$ & 5400 & 24.59 & 23.66 & Pullout \\
\hline 18 & 8HC-B-E-12-1.25B & NSA & $3 \cdot 1 / 16$ & 5400 & 32.48 & 31.25 & $\mathbf{s}$ \\
\hline 18 & $8 H C-B-E-6-1.25 B A$ & $C P A$ & $2-3 / 4$ & 5400 & 20.32 & 19.55 & $\mathbf{s}$ \\
\hline 20 & 8HC-T-E-6-1.25BA & CPA & $3 \cdot 1 / 4$ & 5230 & 18.73 & 18.31 & $\mathbf{s}$ \\
\hline Avg & & & & & & 18.93 & \\
\hline 18 & 8HC-B-E-9-1.25BA & $C P A$ & $3-1 / 16$ & 5400 & 31.67 & 30.47 & $\mathbf{s}$ \\
\hline 20 & BHC-T-E-9-1.25BA & $C P A$ & 3 & 5230 & 31.05 & 30.36 & $\mathbf{s}$ \\
\hline Avg & & & & & & 30.42 & \\
\hline 18 & 8HC-B-E-12-1.25B & $C P A$ & 3 & 5400 & 40.14 & 38.62 & $\mathbf{s}$ \\
\hline 20 & $8 H C-T-E-12-1.25 B$ & $C P A$ & $3-1 / 16$ & 5230 & 35.2 & 34.91 & Pullout \\
\hline Avg & & & & & & 36.77 & \\
\hline 20 & 8HC-T-E-15-1.25B & $\operatorname{CPA}$ & 3 & 5230 & 43.49 & 42.52 & Pullout \\
\hline 20 & $8 H C-T-E-15-1.25 B$ & $\operatorname{CPA}$ & $3-1 / 16$ & 5230 & 42.51 & 41.56 & Pullout \\
\hline Avg & & & & & & 42.04 & \\
\hline 18 & 8HC-B-E-6-1.25BA & TCA & $2-7 / 8$ & 5400 & 11.15 & 10.73 & $\mathbf{T}$ \\
\hline 20 & $8 H C-T-E-6-1.25 B A$ & TCA & $3-1 / 16$ & 5230 & 14.37 & 14.05 & IGC/Cone \\
\hline Avg & & & & & & 12.39 & \\
\hline 18 & 8HC-B-E-9-1.25BA & TCA & $2-3 / 4$ & 5400 & 19.92 & 19.17 & IGC/S/Cone \\
\hline 20 & $8 H C-B-E-9-1.25 B A$ & TCA & 3 & 5230 & 18.36 & 17.95 & IGC \\
\hline Avg & & & & & & 18.56 & \\
\hline 18 & $8 H C-B-E-12-1.25 B$ & TCA & $3-1 / 16$ & 5400 & 28.78 & 27.69 & IGC/Cone \\
\hline 20 & $8 H C-B-E-12-1.25 B$ & TCA & $2-15 / 16$ & 5230 & 28.45 & 22.82 & IGCrCone \\
\hline Avg & & & & & & 25.26 & \\
\hline 20 & 8HC-B:E-13-1.25B & TCA & $2-7 / 8$ & 5230 & 27.54 & 26.92 & lec/s \\
\hline 20 & 8HC-B-E-15-1.25B & TCA & $2 \cdot 13 / 16$ & 5230 & 32.65 & 31.92 & IGCN \\
\hline 18 & 8HC-B-E-6 & CIP & $3-3 / 16$ & 5400 & 30.75 & 29.59 & $s$ \\
\hline 18 & 8HC-B-E-9 & CIP & $2 \cdot 3 / 4$ & 5400 & 28.51 & 27.43 & $\mathbf{s}$ \\
\hline 18 & 8HC-B-E-12 & CIP & $2-7 / 8$ & 5400 & 29.05 & 27.95 & $\mathbf{s}$ \\
\hline 20 & $8 H C-B-E-12$ & CIP & $3-1 / 8$ & 5230 & 31.72 & 31.01 & $\mathbf{s}$ \\
\hline Avg & & & & & & 29.48 & \\
\hline 20 & $8 H C-B-E-15$ & CIP & $2.4 / 5$ & 5230 & 45.28 & 44.22 & $T$ \\
\hline
\end{tabular}

Group 19

\begin{tabular}{llllllll}
\hline \hline 19 & 5VC-E-6-7/8BA & TCB & $1-1 / 2$ & 3960 & 10.70 & 12.02 & S \\
19 & 5VC-E-6-7/8BA & TCB & $1-7 / 16$ & 3960 & 10.88 & 12.23 & T \\
Avg & & & & & & & 12.13
\end{tabular}


Table A.5: Test Results, continued

\begin{tabular}{|c|c|c|c|c|c|c|c|}
\hline $\begin{array}{c}\text { Group } \\
\text { No. }\end{array}$ & $\begin{array}{c}\text { Specimen } \\
\text { label* }\end{array}$ & $\begin{array}{l}\text { Anchorage } \\
\text { method"e }\end{array}$ & $\begin{array}{l}\text { Cover } \\
\text { in. }\end{array}$ & $\begin{array}{l}\text { Concrete } \\
\text { strength } \\
\text { psi }\end{array}$ & $\begin{array}{l}\text { Bond } \\
\text { strength } \\
\text { kips }\end{array}$ & $\begin{array}{c}\text { Mod. bond } \\
\text { strength } \\
\text { kips }\end{array}$ & $\begin{array}{c}\text { Failure } \\
\text { mode }\end{array}$ \\
\hline 19 & 5VC-E-9-7/8BA & TCB & $1-3 / 8$ & 3960 & 18.02 & 20.25 & $\mathbf{S}$ \\
\hline 19 & 5VC-E-9-7/8BA & TCB & $1-1 / 2$ & 3960 & 19.16 & 21.53 & $T$ \\
\hline Avg & & & & & & 20.89 & \\
\hline 19 & 5VC-E-12-7/8BA & TCB & $1-3 / 8$ & 3960 & 22.84 & 25.66 & $T$ \\
\hline 19 & 5VC-E-12-7/8BA & TCB & $1-1 / 2$ & 3960 & 20.85 & 23.43 & Pullout \\
\hline Avg & & & & & & 24.55 & \\
\hline 19 & SVC-E-6.7/8BA & TCA & $1 \cdot 1 / 2$ & 3960 & 8.99 & 7.85 & IGC \\
\hline 19 & 5VC-E-6-7/8BA & TCA & $1 \cdot 7 / 16$ & 3960 & 4.62 & 5.19 & IGcreone \\
\hline Avg & & & & & & 6.52 & \\
\hline 19 & 5VC-E-9-7/8BA & TCA & $1-1 / 2$ & 3960 & 11.90 & 13.37 & IGC/Cone \\
\hline 19 & 5VC-E-9-7/8BA & TCA & $1-3 / 8$ & 3960 & 10.48 & 11.78 & IGC/Cone \\
\hline Avg & & & & & & 12.58 & \\
\hline 19 & 5VC-E-12-7/8BA & TCA & $1-1 / 2$ & 3960 & 15.68 & 17.62 & IGC/Cone \\
\hline 19 & 5VC-E-12-7/8BA & TCA & $1.5 / 8$ & $396 \dot{0}$ & 14.62 & 16.43 & IGC/Cono \\
\hline Avg & & & & & & 17.03 & \\
\hline 19 & 5VC.M-6 & CIP & $1-9 / 16$ & 3960 & 11.64 & 13.08 & $T$ \\
\hline 19 & 5VC-M-6 & CIP & $1-7 / 8$ & 3960 & 11.50 & 12.92 & $T$ \\
\hline Avg & . & & & & & 13.00 & \\
\hline 19 & 5VC-M-9 & CIP & $1 / 9 / 16$ & 3960 & 16.19 & 18.19 & $T$ \\
\hline 19 & SVC-M-9 & CIP & $1-7 / 16$ & 3960 & 20.46 & 22.99 & $T$ \\
\hline Avg & $\cdot$ & & & & & 20.59 & \\
\hline 19 & 5VC-M-12 & CIP & $1-1 / 2$ & 3960 & 25.16 & 28.27 & $\mathbf{T}$ \\
\hline 19 & 5VC-M-12 & CIP & $1-1 / 2$ & 3960 & 23.96 & 26.92 & $\mathbf{s}$ \\
\hline Avg & & & & & & 27.60 & \\
\hline 19 & 5VC-E-6 & CIP & $1-1 / 2$ & 3960 & 11.08 & 12.45 & $\mathbf{T}$ \\
\hline 19 & 5VC-E-6 & CIP & $1 \cdot 1 / 2$ & 3960 & 10.56 & 11.87 & $\mathbf{s}$ \\
\hline Avg & & & & & & 12.16 & \\
\hline 19 & SVC-E-9 & CIP & $1-1 / 2$ & 3960 & 17.11 & 19.23 & $\mathbf{s}$ \\
\hline 19 & 5VC-E-9 & CIP & $1 \cdot 9 / 16$ & 3960 & 15.93 & 17.90 & $\mathbf{S}$ \\
\hline Avg & & & & & & 18.57 & \\
\hline 19 & 5VC-E-12 & CIP & $1-1 / 2$ & 3960 & 22.66 & 25.46 & $\mathbf{s}$ \\
\hline 19 & 5VC-E-12 & CIP & $1-1 / 2$ & 3960 & 22.74 & 25.55 & $\mathbf{s}$ \\
\hline Avg & & & & & & 25.51 & \\
\hline
\end{tabular}

Group 21

\begin{tabular}{llllllll}
\hline \hline 21 & 5HC-T-E-4-7/8BA & CPA & $2-15 / 16$ & 4410 & 7.63 & 8.12 & Pullout \\
21 & 5HC-T-E-6-7/8BA & CPA & $3-1 / 8$ & 4410 & 9.25 & 9.85 & Pullout \\
21 & 5HC-T-E-9-7/8BA & CPA & $2-15 / 16$ & 4670 & 3.53 & 3.65 & Pullout \\
21 & 5HC-T-E-12-7/8B & CPA & 3 & 4410 & 1.50 & 1.60 & Pullout \\
21 & 5HC-T-E-4-7/8BA & TCA & $2-15 / 16$ & 4410 & 8.41 & 8.95 & IGC/S/Cone
\end{tabular}


Table A.5: Test Results, continued

\begin{tabular}{|c|c|c|c|c|c|c|c|}
\hline $\begin{array}{c}\text { Group } \\
\text { No. }\end{array}$ & $\begin{array}{c}\text { Specimen } \\
\text { label" }\end{array}$ & $\begin{array}{l}\text { Anchorage } \\
\text { method }\end{array}$ & $\begin{array}{l}\text { Cover } \\
\text { in. }\end{array}$ & $\begin{array}{l}\text { Concrete } \\
\text { strength } \\
\text { psi }\end{array}$ & $\begin{array}{l}\text { Bond } \\
\text { strength } \\
\text { kips }\end{array}$ & $\begin{array}{l}\text { Mod. bond } \\
\text { strength } \\
\text { kips }\end{array}$ & $\begin{array}{l}\text { Failure } \\
\text { mode }\end{array}$ \\
\hline 21 & 5HC-T-E-6-7/BBA & $\overline{\text { TCA }}$ & 3 & 4410 & 13.01 & 13.85 & IGCICone \\
\hline 21 & 5HC-T-E-9-7/8BA & TCA & 3 & 4670 & 14.18 & 14.67 & IGC/Cone \\
\hline 21 & 5HC-T-E-12-7/8B/ & TCA & $3-5 / 8$ & 4410 & 19.14 & 20.38 & Cone \\
\hline 21 & 5HC-T-E-4 & CIP & 3 & 4870 & 9.26 & 9.58 & $\mathbf{s}$ \\
\hline 21 & 5HC-T-E-6 & CIP & 3 & 4670 & 14.13 & 14.62 & S/Cone \\
\hline 21 & 5HC-T-E-9 & CIP & $3-1 / 16$ & 4410 & 22.17 & 23.61 & S/Cone \\
\hline 21 & 5HC-T-E-12 & CIP & $3-1 / 16$ & 4410 & 26.6 & 28.32 & $T$ \\
\hline 21 & 5HC-B-E-4-7/8BA & CPA & 3 & 4410 & 7.14 & 7.60 & Pullout \\
\hline 21 & 5HC-B-E-6-7/8BA & CPA & 3 & 4410 & 7.2 & 7.67 & Pullout \\
\hline 21 & 5HC-8-E-9-7/8BA & CPA & 3 & 4670 & 6.41 & 6.63 & Pullout \\
\hline 21 & 5HC-B-E-12-7/8B & CPA & 3 & 4410 & 4.18 & 4.45 & Pullout \\
\hline 21 & 5HC-B-E-4-7/8BA & TCA & $2-7 / 8$ & 4410 & 8.04 & 8.56 & IGCrCone \\
\hline 21 & 5HC-B-E-6-7/8BA & TCA & $2 \cdot 7 / 8$ & 4410 & 13.6 & $14: 48$ & Pullout \\
\hline 21 & 5HC-B-E-9-7/8BA & TCA & 3 & 4670 & 12.97 & 13.42 & IGC/Cone \\
\hline 21 & 5HC-B-E-12-7/8B/ & TCA & 3 & 4410 & 20.25 & 21.56 & Cone \\
\hline 21 & 5HC-B-E-4 & CIP & $2 \cdot 7 / 8$ & 4670 & 9.23 & 9.55 & $\mathbf{S}$ \\
\hline 21 & 5HC-B-E-6 & CIP & $3-1 / 8$ & 4670 & 14.74 & 15.25 & $\mathbf{s}$ \\
\hline 21 & 5HC-B-E-9 & CIP & $2-7 / 8$ & 4410 & 23.06 & 24.55 & S/Cone \\
\hline 21 & 5HC-B-E-12 & CIP & 3 & 4410 & 28.39 & 30.23 & $\mathbf{T}$ \\
\hline 21 & 5VC-E-6-7/8BA & TCBNIR & $2-15 / 16$ & 5270 & 14.54 & 14.16 & IGC/T/Cone \\
\hline 21 & 5VC-E-6-7/8BA & TCBNTR & $2 \cdot 15 / 16$ & 5270 & 15.17 & 14.78 & IGC/T/Cone \\
\hline Avg & & & & & & 14.47 & \\
\hline 21 & 5VC.E-9-7/8BA & TCBNTA & $2 \cdot 7 / 8$ & 5270 & 19.89 & 19.37 & $S / T$ \\
\hline 21 & 5VC-E-9-7/8BA & TCBNTR & $3 \cdot 1 / 16$ & 5270 & 24.01 & 23.39 & IGC/S/Cone \\
\hline Avg & & & & & & 21.38 & \\
\hline 21 & 5VC-E-12-7/8BA & TCBNIR & $3 \cdot 1 / 16$ & 5270 & 28.00 & 27.27 & IGCT \\
\hline 21 & 5VC-E-12-7/8BA & TCBNIR & $2-15 / 16$ & 5270 & 27.27 & 26.56 & IGC/T/Cone \\
\hline Avg & & & & & & 26.92 & \\
\hline
\end{tabular}

Group 22

\begin{tabular}{llllllll}
\hline 22 & 5VC-E-6-7/8BA & TCB & 3 & 4980 & 16.57 & 16.60 & S \\
22 & 5VC-E-6-7/8BA & TCB & $3-1 / 8$ & 4980 & 17.37 & 17.40 & S \\
Avg & & & & & & 17.00 & \\
22 & 5VC-E-9-7/8BA & TCB & $2-3 / 4$ & 4980 & 21.61 & 21.65 & S \\
22 & 5VC-E-9-7/8BA & TCB & 3 & 4980 & 26.54 & 26.59 & S/Cone \\
Avg & & & & & & 24.12 & \\
22 & 5VC-E-12-7/8BA & TCB & $3-1 / 16$ & 4980 & 24.11 & 24.16 & T \\
22 & 5VC-E-12-7/8BA & TCB & 3 & 4980 & 25.88 & 25.93 & T \\
Avg & & & & & & 25.05 &
\end{tabular}


Table A.5: Test Results, continued

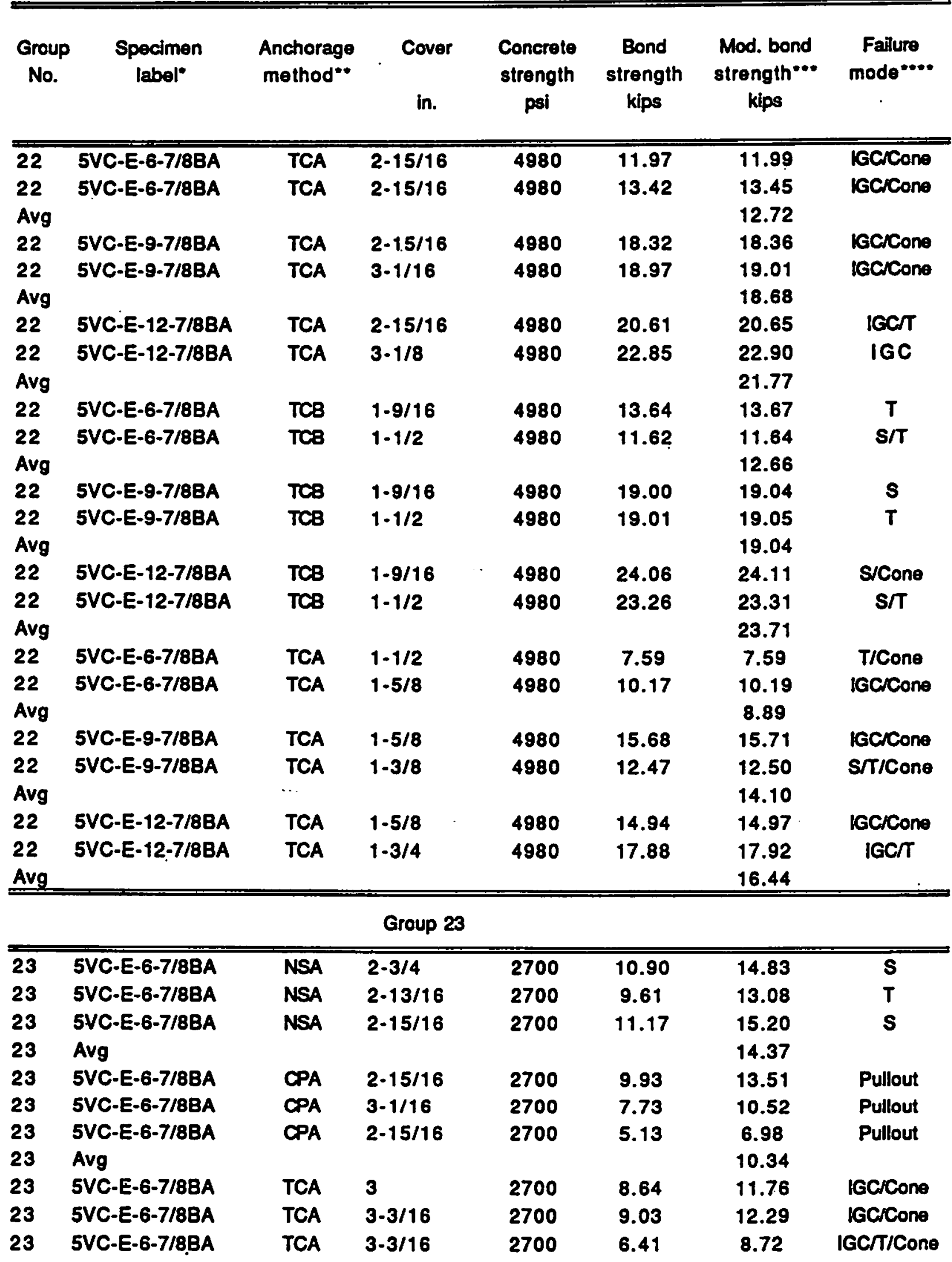


Table A.5:-Test Results, continued

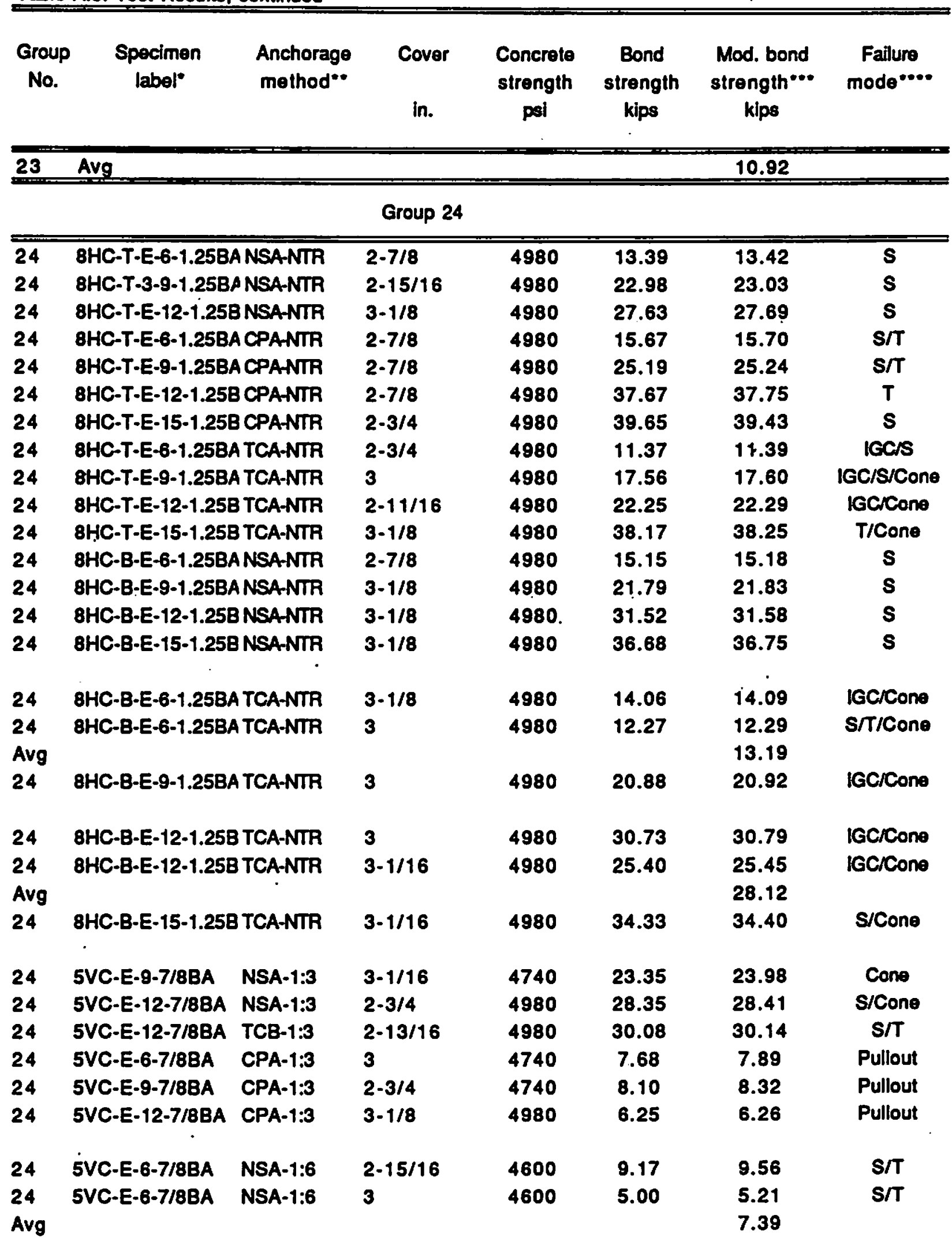


Table A.5: Test Results, continued

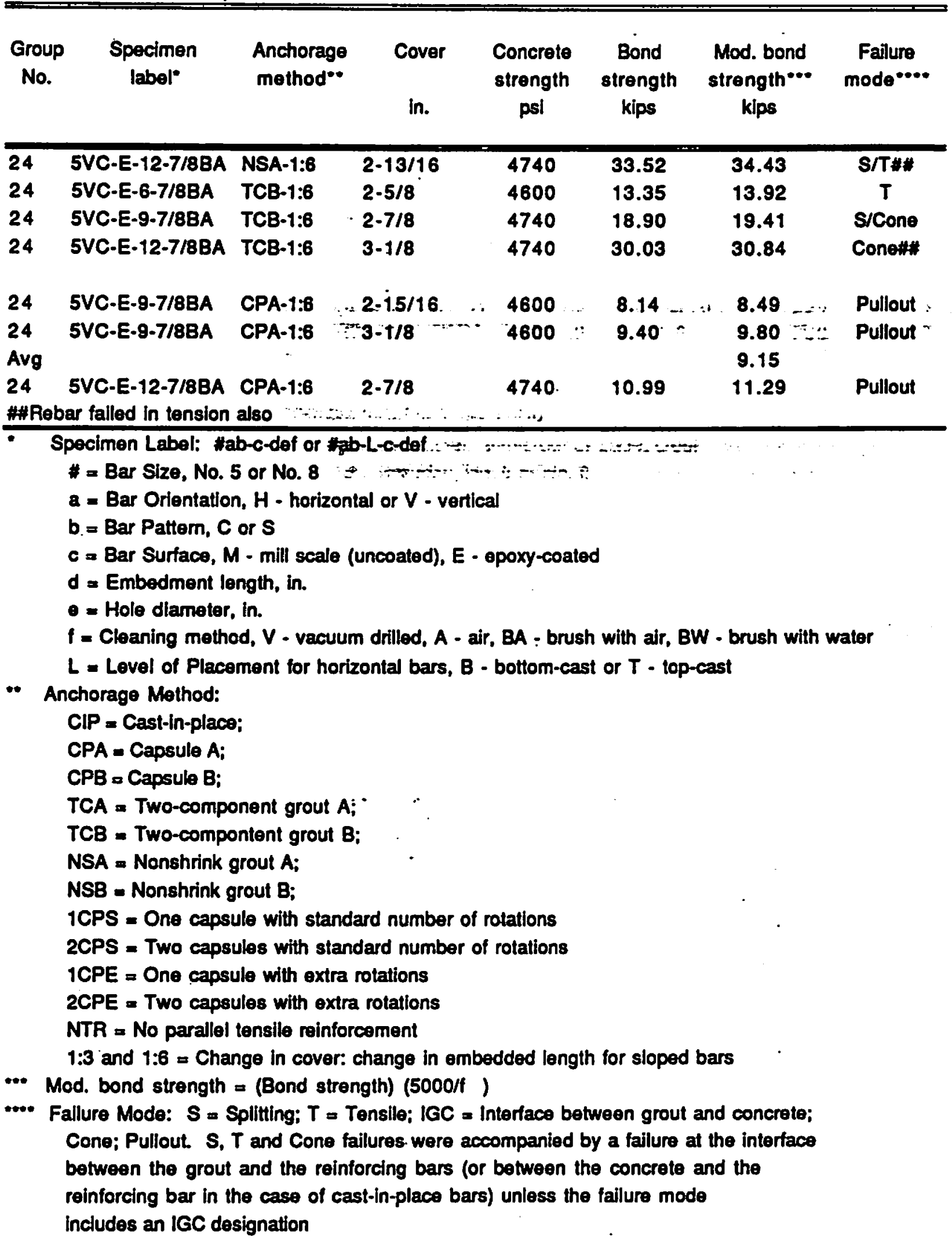

